\title{
Selective Microtubule-Based Transport of Dendritic Membrane Proteins Arises in Concert with Axon Specification
}

\author{
Jennifer D. Petersen, Stefanie Kaech, and Gary Banker \\ Jungers Center for Neurosciences Research, Department of Neurology, Oregon Health and Science University, Portland, Oregon 97239
}

\begin{abstract}
The polarized distribution of membrane proteins to axonal or somatodendritic neuronal compartments is fundamental to nearly every aspect of neuronal function. The polarity of dendritic proteins depends on selective microtubule-based transport; the vesicles that carry these proteins are transported into dendrites but do not enter the axon. We used live-cell imaging of fluorescently tagged dendritic and axonal proteins combined with immunostaining for initial segment and cytoskeletal markers to evaluate different models of dendriteselective transport in cultured rat hippocampal neurons. In mature neurons, dendritic vesicles that entered the base of the axon stopped at the proximal edge of the axon initial segment, defined by immunostaining for ankyrinG, rather than moving into the initial segment itself. In contrast, axonal vesicles passed through the initial segment without impediment. During development, dendrite-selective transport was detected shortly after axons formed, several days before initial segment assembly, before the appearance of a dense actin meshwork in the initial segment, and before dendrites acquire microtubules of mixed polarity orientation. Indeed, some elements of selective transport were detected even before axon specification. These findings are inconsistent with models for selective transport that depend on the presence of an F-actin-based cytoplasmic filter in the initial segment or that posit that transport into dendrites is mediated by dyneins translocating along minus-end out microtubules. Instead our results suggest that selective transport involves the coordinated regulation of the different motor proteins that mediate dendritic vesicle transport and that the selectivity of motor-microtubule interactions is one facet of this process.
\end{abstract}

Key words: axon; dendrite; hippocampus; initial segment; membrane trafficking

\section{Introduction}

Nearly every aspect of neuronal function depends on the polarized distribution of membrane proteins to axonal or somatodendritic compartments. After a sorting step that occurs during budding from the Golgi apparatus (Farías et al., 2012), vesicles containing axonal or dendritic membrane proteins are transported by motor-driven, microtubule-based transport. Vesicles containing axonal proteins enter both axons and dendrites, but their transport is biased toward the axon (Burack et al., 2000; Nakata and Hirokawa, 2003; Wisco et al., 2003). Vesicles containing dendritic proteins are transported efficiently between cell body and dendrites, but do not enter the axon beyond the axon

\footnotetext{
Received Sept. 4, 2013; revised Jan. 15, 2014; accepted Feb. 4, 2014.

Author contributions: J.D.P., S.K., and G.B. designed research; J.D.P. and S.K. performed research; J.D.P., S.K., and G.B. analyzed data; J.D.P., S.K., and G.B. wrote the paper.

This work was supported by NIH Grant MH066179 (G.B.) and P30 NS061800 (P.I., S. Aicher). We thank Julie Luisi and Barbara Smoody for their excellent technical support and all members of the Banker laboratory for their critical comments and helpful suggestions, and we appreciate the guidance provided by members of J.D.P.'s thesis committee, P. Gillespie, J.P. Adelman, and W. Almers.

The authors declare no competing financial interests.

Correspondence should be addressed to Dr Gary Banker, The Jungers Center, Mail Stop L-623, Oregon Health and Science University, 3181 Southwest Sam Jackson Park Road, Portland, 0R 97239. E-mail: bankerg@ohsu.edu.

J. Petersen's present address: University of Bordeaux, Interdisciplinary Institute for Neuroscience, CNRS UMR 5297, F-33000 Bordeaux, France.

DOI:10.1523/JNEUROSCI.3779-13.2014

Copyright $\odot 2014$ the authors $\quad 0270-6474 / 14 / 344135-13 \$ 15.00 / 0$
}

initial segment (Burack et al., 2000; Silverman et al., 2001). Selective transport is likely the primary mechanism by which a polarized distribution of dendritic proteins is achieved (Burack et al., 2000; Arnold, 2009; Kapitein et al., 2010; Jenkins et al., 2012).

The boundary between the somatodendritic and axonal membrane domains is marked by the axon initial segment (Hedstrom et al., 2008), which is thought to play a key role in maintaining the segregation of polarized membrane proteins (Winckler and Mellman, 1999; Winckler et al., 1999; Sobotzik et al., 2009; Szu-Yu Ho and Rasband, 2011). The initial segment also represents the junction between the somatodendritic and axonal cytoskeletons, and has distinctive cytoskeletal features (Palay et al., 1968). Filamentous actin appears to be enriched in the initial segment, although different methods for visualizing actin have led to differing views about its precise organization (Nakada et al., 2003; Song et al., 2009; Al-Bassam et al., 2012; Xu et al., 2013).

Several models have been proposed to account for dendriteselective transport. Kinesins, the molecular motors responsible for most anterograde vesicle transport, recognize biochemical differences between axonal and dendritic microtubules. It has been proposed that the selectivity of motor-microtubule interactions could explain why some vesicles are preferentially transported in one or the other domain (Burack et al., 2000; Setou et al., 2002; Hammond et al., 2010). The polarity orientation of microtubules also differs between axons and dendrites: in axons 
microtubules are predominantly oriented with plus-ends out, whereas dendritic microtubules are of mixed polarity (Baas et al., 1989; Stepanova et al., 2003). Thus dendrite-selective transport could be explained if dendritic vesicles were transported predominantly by dynein, which mediates bidirectional transport in dendrites but could not carry vesicles into the axon (Baas et al., 1989; Kapitein et al., 2010). Filamentous actin in the initial segment could also contribute to selective transport, either by forming a cytoplasmic filter that impedes the transport of dendritic vesicles (Song et al., 2009) or by serving as a substrate for myosinmediated vesicle transport, which could pull vesicles off microtubules and move them back toward the cell body (Lewis et al., 2009; Al-Bassam et al., 2012; Watanabe et al., 2012).

We used high-resolution live-cell imaging to analyze dendrite-selective transport in the context of these different models. Our results show that selective transport arises early in neuronal development, before initial segment assembly and before dendrites acquire minus-end out microtubules.

\section{Materials and Methods}

Animals. Sprague-Dawley rats (Charles River) were housed at the Oregon Health and Science animal care facility. The care of these animals, and experimental procedures involving their use was approved by the Oregon Health and Science University institutional animal care and use committee and met the standards set by the National Institutes of Health guidelines for the humane treatment of animals.

Cell culture, transfection, and drug treatment. Dissociated hippocampal neurons from day 18 rat embryos of either sex were plated at a density of $\sim 18,000$ cells $/ \mathrm{cm}^{2}$ on poly-L-lysine coated coverslips and cocultured over an astroglial feeder layer in N2 medium (Kaech and Banker, 2006). Plasmid DNAs were introduced either by electroporation at the time of plating using an Amaxa Nucleofector device (Lonza) following the manufacturer's suggested protocol or by transfection of cells that had been maintained in culture for 7-9 d using Lipofectamine2000 (Life Technologies). cDNAs encoding the following proteins were used: transferrin receptor (TfR) tagged C-terminally with GFP in the pJPA expression vector (J. Adelman, Oregon Health and Science University, Portland, OR) or in the chicken $\beta$-actin (CAG) expression vector (Niwa et al., 1991); neuron-glia cell adhesion molecule (NgCAM) tagged C-terminally with mCherry or GFP in the CAG vector; rab1 $1 \mathrm{~b}$ tagged $\mathrm{N}$-terminally in the $\mathrm{CAG}$ vector; constitutively active Kinesin-1 (CA-Kinesin-1; KIF5C559) tagged C-terminally with tdTomato (Shaner et al., 2004) in CAG; mRFP in CAG. For experiments investigating the effects of actin depolymerization, latrunculin A $(2.5 \mu \mathrm{M})$ was added $4 \mathrm{~h}$ after neurons were transfected with Lipofectamine and imaging was begun 1-2 h later.

Antibodies and immunostaining. The following primary antibodies were used in this study: mouse anti-ankyrinG (Santa Cruz Biotechnology); chicken anti- $\beta$ IV-spectrin (generously provided by Dr. M. Komada, Department of Biological Sciences, Tokyo Institute of Technology, Tokyo, Japan); mouse anti-sodium channel (Sigma-Aldrich); rabbit anti-MAP2 (Millipore Bioscience Research Reagents); mouse antiacetylated $\alpha$ tubulin (Sigma-Aldrich); mouse anti-polyglutamylated $\alpha / \beta$ tubulin (Sigma-Aldrich); mouse anti-Tau-1 (Millipore Bioscience Research Reagents). All secondary antibodies were obtained from Jackson ImmunoResearch Laboratories.

Neurons were fixed in warmed 4\% paraformaldehyde in PBS containing $4 \%$ sucrose, rinsed in PBS, and then permeabilized in $0.25 \%$ Triton $\mathrm{X}-100$ in PBS (Sigma-Aldrich) for $5 \mathrm{~min}$ at room temperature. Coverslips were then rinsed in PBS and blocked for $60 \mathrm{~min}$ in $1 \%$ fish gelatin (Sigma-Aldrich) in PBS. Coverslips were incubated in primary antibody diluted in blocking solution for $1 \mathrm{~h}$, blocked again for $60 \mathrm{~min}$, and then incubated in secondary antibodies for $30 \mathrm{~min}$. Coverslips were rinsed in PBS, water, and mounted in elvanol mounting medium.

Imaging and analysis of immunostained neurons. Images of fixed cells were acquired using a Leica DM-RXA widefield microscope with either a $60 \times / 1.32$ NA or $40 \times / 1.25$ NA PlanApo objective lens on a Princeton Instruments MicroMax Interline CCD camera and analyzed using Meta-
Morph software (Molecular Devices). To evaluate the distribution of initial segment proteins relative to microtubule specializations in mature neurons, the integrated intensity of immunofluorescence at each pixel along a $1-\mu \mathrm{m}$-wide $\times 70-\mu \mathrm{m}$-long line drawn along the proximal axon was logged and background was subtracted from each pixel value. For ankyrinG, $\beta \mathrm{IV}$-spectrin, and MAP2 staining, background was taken as the average intensity of staining in the axon beyond the initial segment. For Tau-1, polyglutamylated and acetylated microtubules, background was estimated from the average intensity in empty areas of the coverslip. For each cell, fluorescence intensity was normalized so that the brightest pixel was set to $100 \%$. Line scan values from 10 to 20 cells for each immunostain were averaged to generate a composite line scan. The accumulation of ankyrinG, $\beta \mathrm{IV}$-spectrin, and voltage-dependent sodium channels at the initial segment during development (2-20 DIV) was quantified similarly. After subtracting background, the integrated intensity per pixel in the proximal $50 \mu \mathrm{m}$ of the axon was averaged. Ten to 20 cells per time point from three separate experiments were averaged and results were pooled.

Imaging vesicle transport. Coverslips with attached neurons were loaded into a sealed heated chamber (Warner Instruments) in phenolred-free imaging medium (Hank's balanced salt solution buffered to $\mathrm{pH}$ 7.4 with $10 \mathrm{~mm}$ HEPES and supplemented with $0.6 \%$ glucose). Vesicle transport was imaged using either a conventional "wide-field" microscope or a spinning disk confocal microscope. For conventional microscopy, images were acquired using a Leica DM-RXA microscope with a $63 \times$ Plan Apo 1.32 NA objective lens and a MicroMax Interline CCD camera (Princeton Instruments). Exposures were streamed continuously for $30 \mathrm{~s}$ or longer. The spinning disk microscope consisted of a Yokogawa CSU-10 spinning disk confocal head mounted on a Nikon TE2000 inverted microscope with $60 \times / 1.45$ NA Plan Apo objective and with illumination from a Innova 70C Spectrum ion laser (Coherent). Streams of images (350-800 ms exposures) were captured using a Orca ER CCD camera (Hamamatsu Instruments). Dual-color recordings were acquired by fast sequential imaging (500 ms exposure per channel).

Vesicle transport analysis. Kymographs were generated using MetaMorph software. Contrast was inverted such that fluorescent organelles in the original image corresponded to dark lines in the kymograph. To measure transport, straight lines were traced on the kymographs to approximate each vesicle excursion and the coordinates of the lines were transferred to an Excel spreadsheet to calculate the velocity and run length of each transport event. We also determined the total number of transport events (normalized to account for variations in neurite length and recording duration). To assess overlap in dual color recordings, kymographs were prepared as above for recordings in each color channel, and then lines from the green kymograph were transferred to the red kymograph and vice versa.

\section{Results}

\section{Characteristics of the transport vesicles that convey axonal and dendritic membrane proteins}

We used two-color, live-cell spinning disk confocal imaging to compare the transport characteristics of vesicles containing axonal versus dendritic proteins in mature hippocampal neurons (Dotti et al., 1988, their Stage 4). Vesicles containing dendritic proteins were labeled by expressing TfR-GFP. Vesicles labeled with TfR also contain other dendritically polarized proteins, including NMDA and metabotropic glutamate receptors (Farías et al., 2012); depending on the expression time, between one-third and two-thirds of the vesicles labeled with TfR-GFP are endosomes, based on labeling with transferrin or with rab11b (see latrunculin A experiments described in Fig. 5; Burack et al., 2000). Axonal vesicles were labeled by expressing NgCAM, an axonal cell adhesion molecule, which was tagged with mCherry (NgCAM-mCherry). Recordings were made 6-8 h after transfection with Lipofectamine 2000. Elements labeled with TfR-GFP ranged from small vesicles to $1-\mu \mathrm{m}$-long tubules; they moved bidirectionally in dendrites but were essentially absent from the 

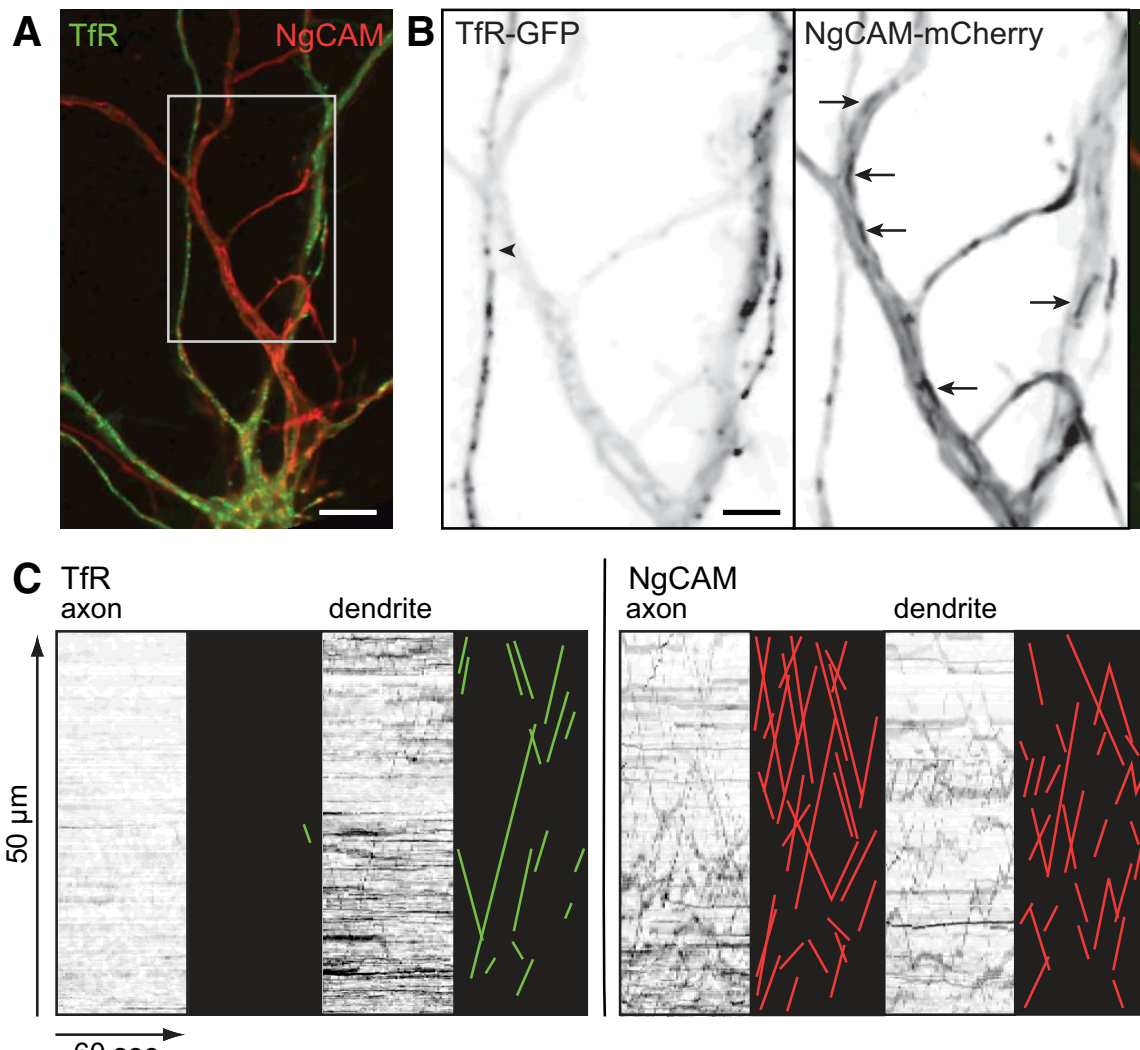

\begin{abstract}
$\mathrm{NgCAM}$
\end{abstract}
axon

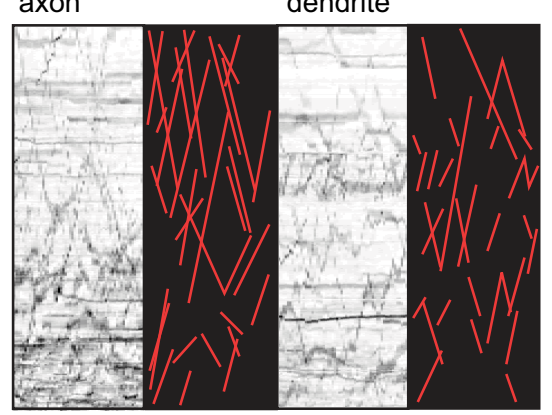

dendrite

Figure 1. Dendritic and axonal membrane proteins are transported in distinct vesicles. $\boldsymbol{A}$, An overlay image of the proximal axon and dendrites of a cell coexpressing TfR-GFP (green) and $\mathrm{NgCAM}$-mCherry (red). $\boldsymbol{B}$, The enlarged view of the boxed area in $\boldsymbol{A}$ shows the small vesicles labeled by TfR-GFP in dendrites (arrowhead) and the larger NgCAM-mCherry tubules present in both the axon and dendrites (arrows). Boxed area shown as color overlay to right. C, Kymographs generated from dual-color recordings show vesicle transport of TfR-GFP or NgCAM-mCherry labeled vesicles in the axon and dendrite segments shown in $\boldsymbol{A}, \boldsymbol{B}$. Anterograde or retrograde transport events appear as positively (anterograde) or negatively (retrograde) sloping lines in the kymographs. To facilitate viewing of the transport events, lines were traced manually and are shown to the right of each kymograph as an illustration. TfR-GFP transport events are encoded green and NgCAMmCherry transport events encoded red. Overlaid kymograph illustrations show that TfR-GFP transport events are virtually absent in the axon, whereas nonoverlapping transport events of both proteins are abundant in the dendrite. Kymographs are shown with time in the $x$-axis, and distance moving away from the cell body in the $y$-axis. Contrast in images was nonlinearly adjusted to improve visibility of dim moving vesicles and the grayscale was inverted so that fluorescence in the image appears black (B, $)$. Scale bars: $\boldsymbol{A}, 10 \mu \mathrm{m} ; \boldsymbol{B}, 5 \mu \mathrm{m}$.

axon (Fig. 1). NgCAM-mCherry labeled long tubulovesicular organelles that moved bidirectionally in dendrites and predominantly in the anterograde direction in axons. In their shape and transport properties, the NgCAM-mCherry organelles closely resembled the tubulovesicular elements that have been previously identified as carriers for several other axonal membrane proteins, including APP and GAP-43 (Kaether et al., 2000; Nakata and Hirokawa, 2003).

Kymographs, such as those shown in Figure $1 C$, were used to analyze the transport properties of the vesicles labeled by NgCAM-mCherry and TfR-GFP and determine whether there was overlap between axonal and dendritic vesicle populations. NgCAM vesicles underwent continuous long-range movements in the axon, predominantly in the anterograde direction. In dendrites, both TfR and NgCAM vesicles moved bidirectionally and the length of individual excursions appeared shorter than those in the axon. Based on a comparison of TfR and NgCAM kymographs, at most only a few percentages of vesicles were labeled with both proteins. This result indicates that these two proteins are efficiently sorted into distinct vesicle populations with very different patterns of transport.

\section{The behavior of dendritic transport vesicles at the base of} the axon

Previous observations show that vesicles containing dendritically polarized proteins are seldom found beyond the initial segment and several different models have been proposed to account for this observation (Lewis et al., 2009; Song et al., 2009; Kapitein et al., 2010). To gain further insight into the process that excludes dendritic vesicles from the axon, and in particular, how the region of exclusion relates to the geometry of the initial segment, we carefully analyzed the movements of dendritic vesicles labeled with TfR-GFP at the base of the axon. After live-cell imaging, the neurons were fixed and immunostained for ankyrinG, a marker of the initial segment membrane specialization. The cells that had been imaged were then relocated and the immunostained images were overlaid with live-cell recordings to correlate the behavior of TfR-GFP-labeled vesicles with respect to the initial segment.

An example of a neuron expressing TfR-GFP is shown in Figure 2, and Movie 1 shows the movements of TfR-GFP vesicles. As expected, TfR-GFP-labeled vesicles were observed in the dendrites and the first few micrometers of the axon, but were absent in the distal axon. Figure $2 C$ shows a kymograph that depicts the movements of two vesicles whose ultimate fates could be clearly determined. The first stopped abruptly after reaching $7.3 \mu \mathrm{m}$ into the axon and paused for $20 \mathrm{~s}$. Subsequently a second vesicle entered and stopped at the same location. A few seconds later, the second vesicle reversed and was transported back to the cell body while the first vesicle underwent exocytosis (marked by a transient increase in intensity when the GFP was exposed to the higher $\mathrm{pH}$ of the extracellular medium). The location of ankyrinG staining in this cell (Fig. 2C, red shading) shows that the 
TfR-labeled vesicles moved $2.5 \mu \mathrm{m}$ into the initial segment before stopping. Another example from a second neuron (Fig. $2 C$, right) shows a similar pattern; a TfRGFP-labeled vesicle advanced $9 \mu \mathrm{m}$ into the axon $(3.5 \mu \mathrm{m}$ into the domain of ankyrinG staining), paused for $6 \mathrm{~s}$, and then fused with the plasma membrane.

In all, we analyzed seven cells in which it was possible to unambiguously follow eight TfR-GFP-labeled vesicles and determine their fate. Of these, four vesicles entered the axon, paused, and then fused with the plasma membrane, and four paused and then returned back toward the cell body (Fig. 2D). Although the position where dendritic vesicles stopped varied from cell to cell (ranging from $\sim 3$ to 10 $\mu \mathrm{m}$ from the cell body), in nearly every case this point was $\sim 2 \mu \mathrm{m}$ beyond the proximal boundary of ankyrinG staining $(1.6 \pm 2.6$, mean $\pm S D)$. In cortical neurons, Al-Bassam et al. (2012) also found that most dendritic vesicles are arrested within $10 \mu \mathrm{m}$ of the cell body. As the average length of ankyrinG staining at the initial segment is $\sim 20 \mu \mathrm{m}$, dendritic vesicles only penetrate the proximal $10 \%$ of the initial segment. Dendritic transport vesicles stop abruptly when they reach this point. Until they stop moving, their velocity at the base of the axon is similar to that of the vesicles moving within the dendrites $(0.62 \pm 0.36 \mu \mathrm{m} / \mathrm{s}$ at base of axon; $0.75 \pm 0.38 \mu \mathrm{m} / \mathrm{s}$ in dendrites; $p>0.29$ ). We did not observe examples of dendritic vesicles that slowed gradually and came to a stop far into the initial segment, as predicted by the cytoplasmic filter model.

Unlike dendritic vesicles, axonal vesicles pass through the initial segment. The cytoplasmic filter model of Song et al. (2009) predicts that axonal vesicles slow as they pass through the dense actin meshwork of the initial segment, then accelerate as they enter the axon proper. We used kymograph analyses to determine the velocities of NgCAM-labeled vesicles as they traversed the proximal axon (Fig. 3). Based on analysis of 82 vesicles from five cells, the velocity of NgCAM-labeled vesicles within the initial segment (10-30 $\mu \mathrm{m}$ from the cell body) was not significantly different from in the axon proper (80-100 $\mu \mathrm{m}$ from the cell body): initial segment velocity: $2.5 \pm 1.1 \mu \mathrm{m} / \mathrm{s}$; distal axon velocity: $2.8 \pm 1.0 \mu \mathrm{m} / \mathrm{s}(p \geq 0.05)$. Many individual vesicles could be followed along the axon for up to $100 \mu \mathrm{m}$, as they traveled in regions proximal to, within, and distal to the initial segment. Such vesicles moved at constant rates throughout, without the slightest indica-

\section{A}
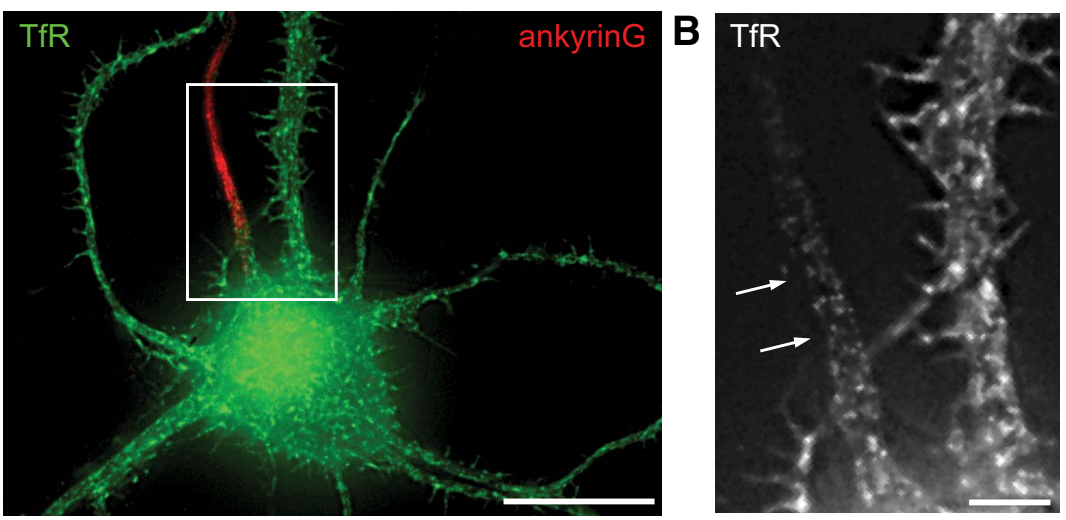

C

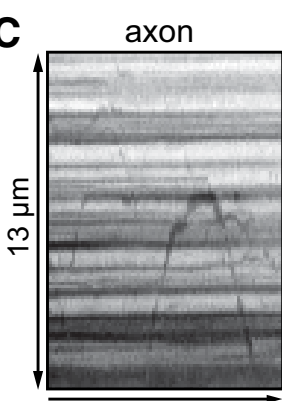

$48 \mathrm{sec}$

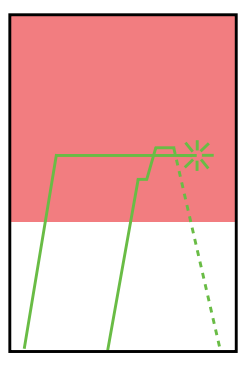

D

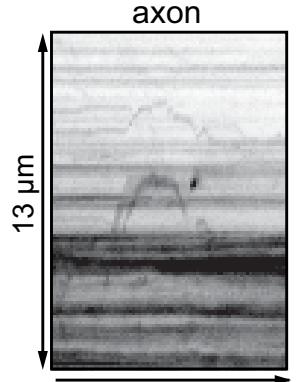

$48 \mathrm{sec}$

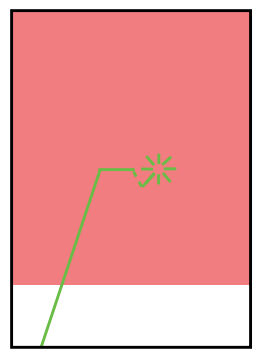

\section{.}
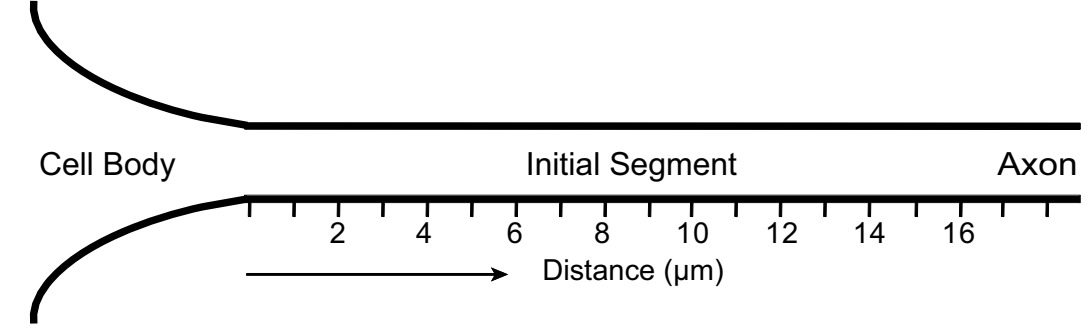

TfR-GFP vesicle

ankyrinG staining

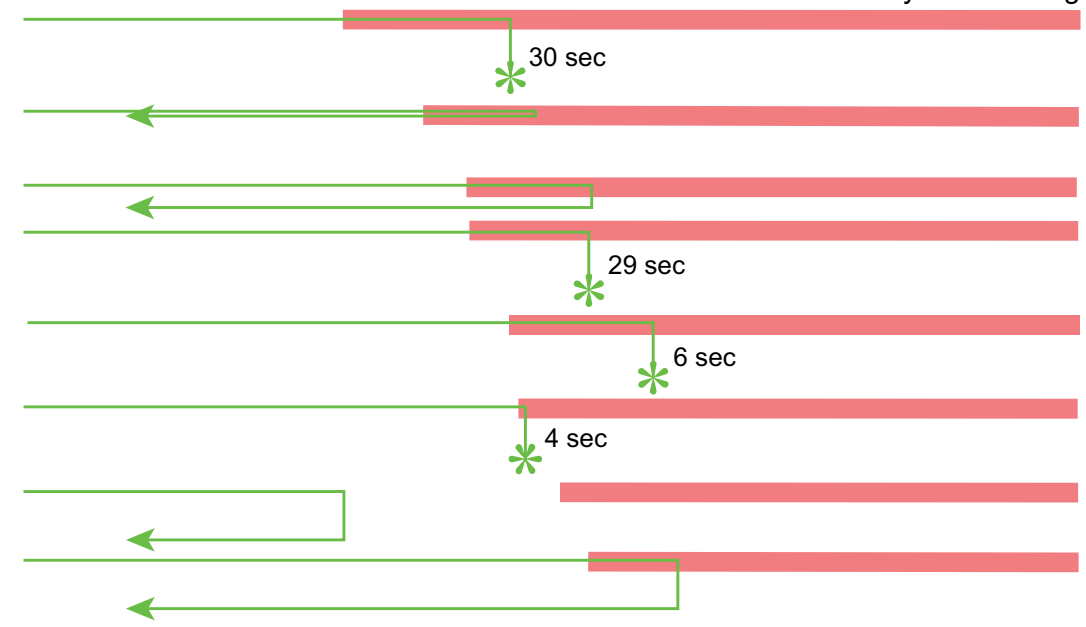

Figure 2. Dendritic vesicles are blocked at the proximal edge of the initial segment. $A$, A color overlay image of a neuron electroporated with TfR-GFP, live-imaged at 10 DIV by wide-field microscopy, then fixed and immunostained for ankyrinG. $\boldsymbol{B}$, An enlarged view of the boxed area in $\boldsymbol{A}$ shows that TfR fluorescence is absent in the region of ankyrinG immunostaining (arrows). $\boldsymbol{C}$, Left, a kymograph generated from the live-cell recording of the cell area shown in $\boldsymbol{B}$ with an illustration depicting movement of vesicles (green lines) and location of ankyrinG staining (red shading). Two TfR-GFP labeled vesicles entered the axon, abruptly stopped upon reaching proximal edge of ankyrinG immunostain, and then either reversed (dashed line) or fused (asterisk) with the plasma membrane. Movie 1 shows the video of transport in this cell relative to ankyrinG. The same behavior was observed in the axon of a second cell ( $\boldsymbol{C}$, right): a TfR-GFP labeled vesicle reached the proximal boundary of ankyrinG immunostain, stopped, then fused with the plasma membrane. $\boldsymbol{D}$, A diagram summarizing the spatial relationship between the reversal point for TfR vesicles (where vesicles stop and fuse or reverse course) and the location of ankyrinG staining in seven different neurons. Contrast in images was nonlinearly adjusted to improve visibility of dim moving vesicles. All neurons were imaged at $10-12$ DIV; $n=7$ cells. Scale bars: $\boldsymbol{A}, 20 \mu \mathrm{m} ; \boldsymbol{B}, 5 \mu \mathrm{m}$. 


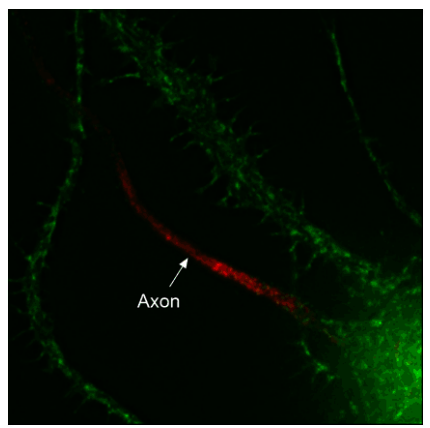

Movie 1. Dendritic vesicles are blocked at the proximal edge of the initial segment. A neuron (10 DIV) electroporated with TfR-GFP (green) and immunostained for ankyrinG (red) is shown followed by the recording of intracellular transport of TfR-GFP (white). Dendritic vesicles are blocked at proximal edge of the initial segment. Streamed time-lapse images were acquired at 1.68 frames per second for $48 \mathrm{~s}$. Movie is played at 20 frames per second.

tion of slowing within the initial segment (Movie 2; live-cell recording of the cell shown in Fig. 3). These observations indicate that the mechanisms that cause dendritic vesicles to stop abruptly at the proximal edge of the initial segment have no apparent effect on the transport velocity of axonal vesicles.

\section{The initial segment is a specialized cytoskeletal domain}

The biochemical specializations that distinguish axonal from dendritic microtubules also change in the proximal axon. We wondered how this microtubule transition zone relates to the membrane specializations that mark the initial segment and to the site where dendritic vesicle transport stops. Using doublelabel immunostaining, we compared the distribution of different microtubule markers with the position of immunostaining for either ankyrinG or $\beta I V$-spectrin to mark the initial segment (Fig. 4). Staining for MAP2, a marker of dendritic microtubules, dropped sharply at the point where staining for the initial segment markers increased (Fig. 4A, B). Staining for Tau-1, which is enriched in axonal microtubules, increased at the distal end of the initial segment (Fig. 4C,D) and continued to rise beyond the initial segment, in a proximo-distal gradient. Axonal microtubules are also enriched in two posttranslational modifications of tubulin, acetylation and polyglutamylation (Hammond et al., 2010). Like the pattern seen for Tau-1 staining, immunostaining for these tubulin modifications was low in the proximal axon, began to increase $\sim 20 \mu \mathrm{m}$ from the cell body, and continued to rise well beyond the initial segment (Fig. $4 E-H$ ). A composite linescan, based on analysis of $8-17$ cells stained with each marker, shows that the microtubules in the initial segment are not enriched in either markers of dendritic or axonal microtubules (Fig. $4 I)$. Thus, the initial segment constitutes a unique cytoskeletal domain within the neuron. The reversal point for dendritic vesicles roughly corresponds to the point where MAP2 staining declines but is well proximal to the point where Tau- 1 staining and axonal posttranslational modifications of microtubules begin.

\section{Disrupting filamentous actin with latrunculin A interferes with the sorting of dendritic proteins}

Previous reports show that treatment of neurons with drugs that disrupt filamentous actin leads to a loss in the polarization of membrane proteins (Song et al., 2009; Al-Bassam et al., 2012). This result has been attributed to a disruption of actin filaments in the initial segment (Song et al., 2009). To further investigate how actin disruption affects polarized vesicle transport, we coexpressed TfR-GFP and NgCAM-mCherry to label dendritic and axonal vesicles, then evaluated their transport 60-120 min after exposure to latrunculin A (Fig. 5; Movie 3). In latrunculin A-treated cells, TfR was no longer polarized to the somatodendritic domain and TfR-labeled vesicles readily passed from the cell body into the axon. Many TfR vesicles underwent long anterograde excursions in the axons, a finding never observed in control cells. We also noticed that the morphology of the organelles labeled with TfR was different. Rather than the small vesicles seen in control neurons, TfR-GFP labeled long, tubulovesicular structures in cells exposed to latrunculin A, similar to the vesicles that carry axonal proteins in control cells (Fig. 1). This result raises the possibility that latrunculin A disrupts the process that segregates dendritic and axonal protein into different populations of transport vesicles.

To address this possibility, we examined the degree of overlap between TfR-GFP and NgCAM-mCherry in cells coexpressing both constructs. These results are quantified in Table 1, which compares the characteristics of vesicles undergoing anterograde axonal transport in control and latrunculin A-treated cultures. In control neurons, $\sim 90 \%$ of the vesicles undergoing anterograde transport in the axon were labeled exclusively with NgCAMmCherry. Only a few dimly labeled TfR vesicles were transported into the axon and these were not colabeled with NgCAM. Following latrunculin treatment, the number of TfR-labeled vesicles in the axon increased dramatically, so that they accounted for $73 \%$ of all axonal vesicles (compared with only $11 \%$ of axonal vesicles in control neurons). Importantly, in latrunculin-treated cells, $73 \%$ of the TfR-labeled vesicles in the axon colabeled with NgCAM-mCherry, compared with $2.5 \%$ in control cells. Rather than altering the selectivity of vesicle transport, these observations indicate that latrunculin A disrupts the selectivity of protein sorting, allowing dendritic proteins to enter vesicles that are normally targeted to the axon. To determine whether the TfR vesicles entering the axon in latrunculin-treated cells were derived from the Golgi complex or were endosomes, we labeled endosomes by exposing cells to Alexa568 transferrin. In recordings from eight cells, we observed many vesicles in the dendrites that were labeled with both TfR-GFP and labeled transferrin, but of 65 TfR-labeled vesicles that entered the axon only one was transferrin-positive. Thus, most of the TfR vesicles that enter the axon in cells exposed to latrunculin A are derived from the Golgi complex. The selective transport of dendritic endosomes does not appear to be affected by latrunculin treatment. These results show that the loss of polarity of dendritic proteins caused by disrupting actin filaments involves alterations in protein sorting in addition to the effects on the actin cytoskeleton within the initial segment previously reported (Song et al., 2009; Al-Bassam et al., 2012).

\section{Selective dendritic transport arises early in neuronal development}

In cultured hippocampal neurons axon specification marks the transition between Developmental Stages 2 and 3 (Dotti et al., 1988). On average, $50 \%$ of cells have developed axons by $\sim 24 \mathrm{~h}$ after plating (Jareb and Banker, 1997; Esch et al., 2000). The accumulation of initial segment proteins and the development of the initial segment diffusion barrier occur at a significantly later stage in development (Nakada et al., 2003; Song et al., 2009). For example, in our hands only approximately half the neurons show a detectable enrichment in ankyrinG immunostaining by 4 DIV and mature levels of ankyrinG in the initial segment are not reached until 14 DIV (Boiko et al., 2007; Hedstrom et al., 2007; Yang et al., 2007; data not shown). The enrichment of filamentous actin in the initial segment also occurs well after axon for- 
A NgCAM-GFP

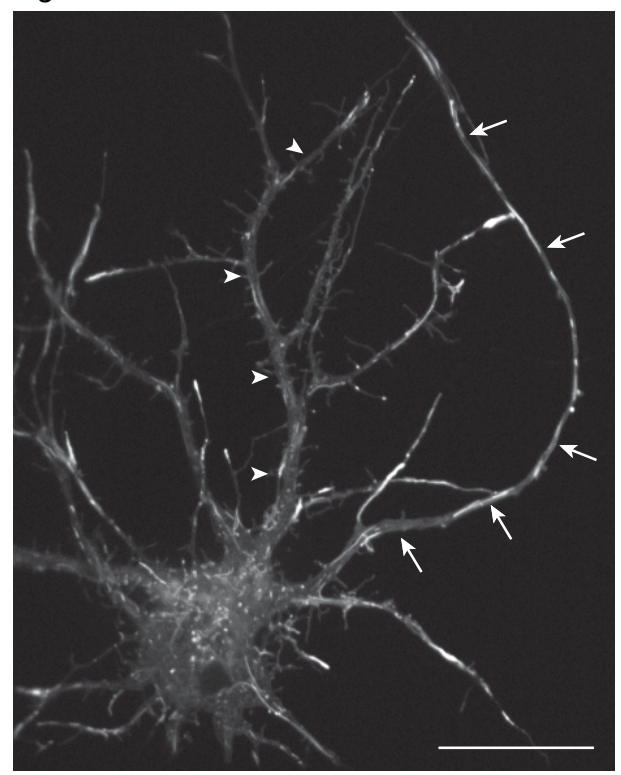

B

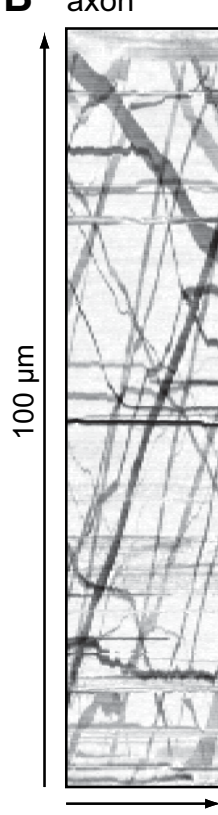

$40 \mathrm{sec}$

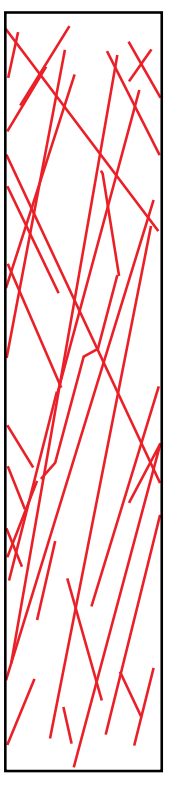

C dendrite

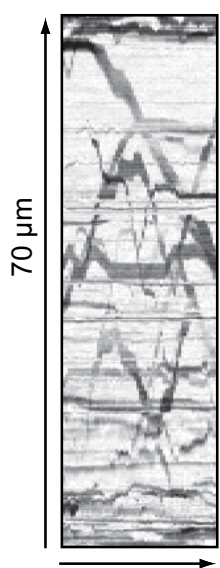

$40 \mathrm{sec}$

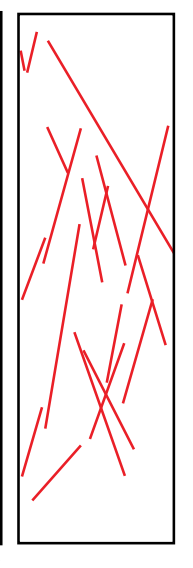$$
\text { . }
$$

Figure 3. Axonal vesicles move through the initial segment at a constant velocity. A, A neuron expressing NgCAM-GFP 6 - 8 h after Lipofectamine 2000 transfection was imaged using a spinning disk confocal microscope to record the transport of axonal vesicles. Arrows indicate the axon; arrowheads indicate a dendrite. The live-cell recording of this cell is shown in Movie 2 . Contrast in the image was nonlinearly adjusted to improve visibility of dim moving vesicles. $\boldsymbol{B}$, Kymographs showing transport of NgCAM-GFP in the segment of dendrite and axon indicated in $\boldsymbol{A}$. Illustrations of each kymograph with transport events drawn in red are shown to the right of each kymograph. Neuron was imaged at 10 DIV. Scale bar, $20 \mu \mathrm{m}$.

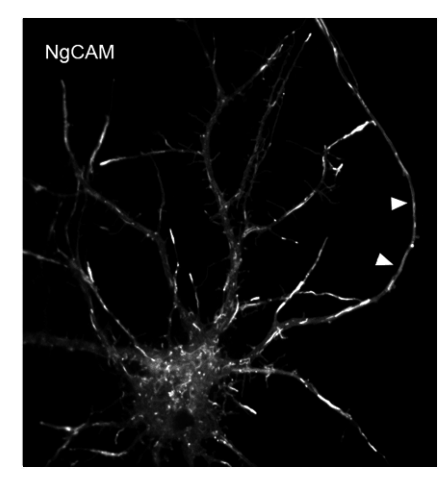

Movie 2. Axonal vesicles move continuously through the initial segment. Tubulovesicular organelles labeled with the axonal protein, $\mathrm{NgCAM-GFP}$, are not slowed as they transport into the axon (solid arrowheads), through the region of the initial segment. Stream time-lapse images were acquired at 1.5 frames per second for 40 s. Movie is played at 15 frames per second.

mation (Song et al., 2009). Likewise the population of minus-end out microtubules in developing dendrites first appears around day 4 and their proportion increases until approximately day 10 (Baas et al., 1989). We wondered how the development of selective dendritic transport related to these other events in neuronal maturation.

To determine whether selective transport could be detected in cells that had just formed axons, we electroporated neurons with TfR-GFP at the time of plating and imaged transport of TfR-GFP vesicles $24 \mathrm{~h}$ later. Figure 6 and Movie 4 illustrate a cell from this series of experiments. Numerous TfR-GFP labeled vesicles entered each of this cell's five minor neurites, traveled to their tips, and then reversed back toward the cell body. In contrast, vesicles entered the proximal axon but did not travel more than $\sim 25 \mu \mathrm{m}$ from the cell body. As illustrated in Figure $6 C$, one vesicle traveled $22 \mu \mathrm{m}$ into the axon, paused for $67 \mathrm{~s}$, and then fused with the plasma membrane. Two other vesicles advanced $\sim 7 \mu \mathrm{m}$ from the cell body, reversed direction, and exited the axon. TfR-GFP fluorescence was detectable in the distal axon, but these elements were largely stationary or occasionally moved retrograde. These structures likely represent TfR that was already present in this neurite at Stage 2 of development, before it elongated and became the axon.

We analyzed kymographs of eight Stage 3 neurons expressing TfR-GFP and compared the number of anterograde transport events in the minor neurites and the axon as a function of distance from the cell body (Fig. 6D). There were on average $5.5 \pm$ 0.9 anterograde events $/ 5 \mu \mathrm{m} / \mathrm{min}$ in the minor neurites and this did not vary as a function of distance from the cell body. Fewer vesicles entered the base of the axon than the minor neurites; by $30 \mu \mathrm{m}$ from the cell body there were 10 times fewer anterograde events than in the minor neurites. Beyond this point, there were virtually no anterograde events in the axon, except for a few short-range movements of dimly labeled puncta.

These results indicate that the exclusion of dendritic vesicles from the axon arises early in neuronal development, several days before the formation of the initial segment or the appearance of minus-end out microtubules in dendrites. In contrast to the situation in mature neurons, where the reversal point for dendritic vesicles occurs at a well defined point $\sim 10 \mu \mathrm{m}$ from the soma, in Stage 3 cells the reversals occur in a zone between 5 and $30 \mu \mathrm{m}$ from the cell body.

\section{Selective transport of vesicles containing dendritic proteins can be detected before axon specification}

CA-Kinesin-1, generated by deleting the autoinhibitory tail domain, translocates selectively on axonal microtubules and accumulates at axon tips (Nakata and Hirokawa, 2003; Jacobson et al., 2006); at Stage 2 of development, before the axon has formed, this motor selectively accumulates at the tips of only one or two mi- 
A

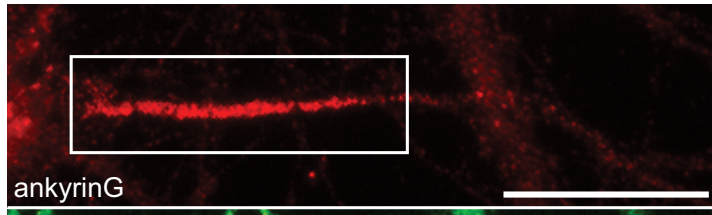

B
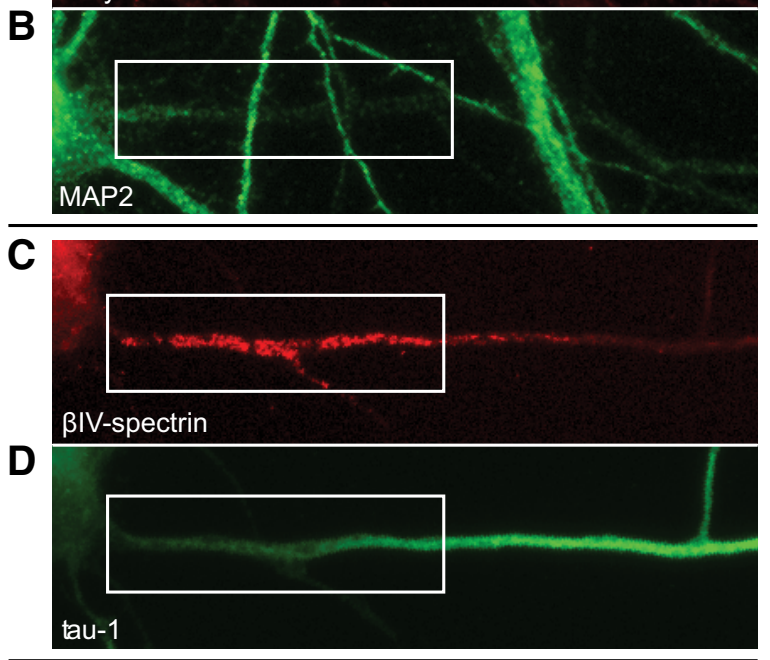

E

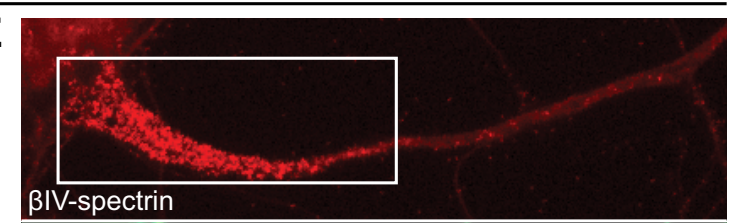

$\mathbf{F}$
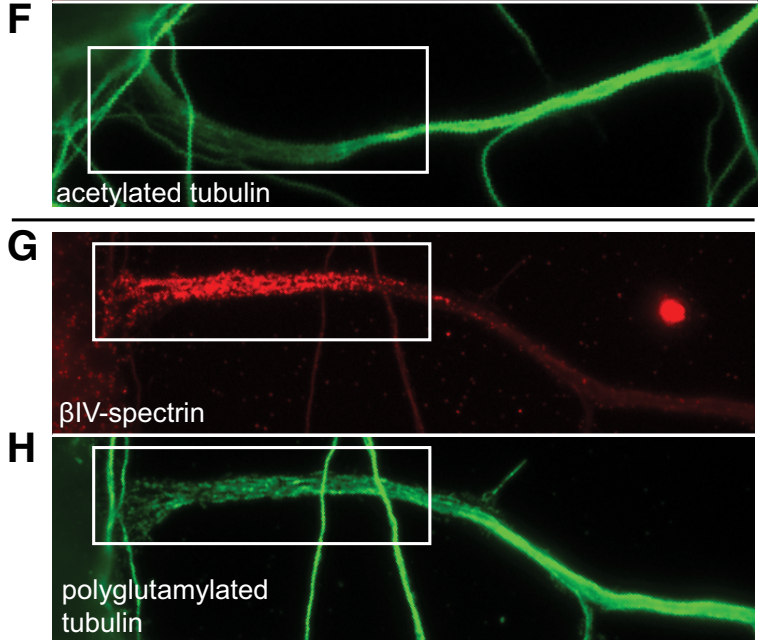

I

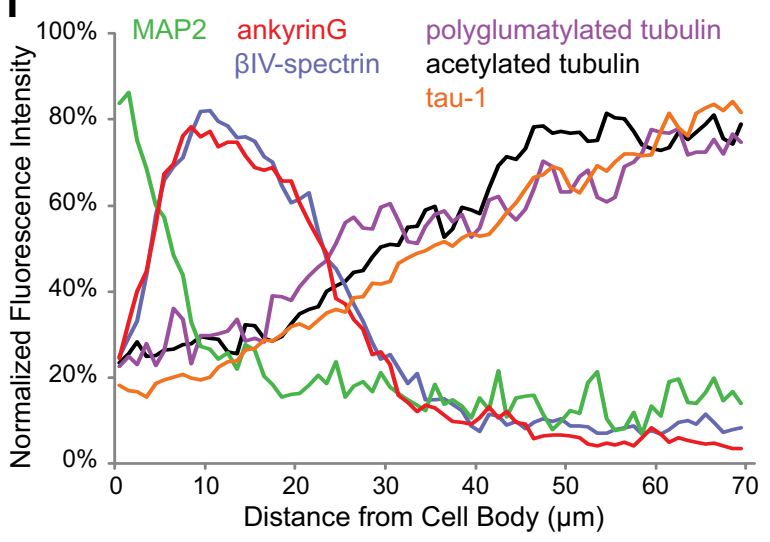

Figure 4. The initial segment is a unique cytoskeletal domain. $\boldsymbol{A}-\boldsymbol{H}$, Images of the proximal axon of neurons double-stained for different combinations of initial segment and cytoskeletal nor neurites (Jacobson et al., 2006). These results indicate that Kinesin-1 recognizes differences in the microtubule cytoskeleton in different Stage 2 neurites, even though these neurites appear morphologically identical. This raises the question of whether vesicles containing dendritic membrane proteins may also be transported selectively into a subset of Stage 2 neurites.

To address this question, we imaged vesicle transport in Stage 2 neurons that had accumulated CA-Kinesin-1 in a subset of neurites. In this set of experiments, the membrane associated small GTPase rab11b, which labels endosomes that mediate the recycling of TfR (Schlierf et al., 2000), was chosen as a vesicle marker because it does not accumulate in the plasma membrane, thus enhancing the ability to detect vesicle transport in these short neurites. As vesicles labeled with TfR, GFP-rab11b-labeled vesicles were selectively excluded from the axon at Stages 3 and 4 of development (data not shown).

A representative cell from this series of experiments is shown in Figure 7 and Movie 5. In this cell, CA-Kinesin-1 accumulated at the tips of two of the cell's four neurites (neurites 1 and 3). Kymographs illustrating the transport of rab11b-labeled vesicles in this cell show that there were far more anterograde movements, and longer anterograde movements in neurites that lacked CA-Kinesin-1 (neurites 2, 4, and 5) than in those where the motor construct accumulated (neurites 1 and 3; Fig. 7C). This is what would be expected if dendritic vesicles preferentially avoided those Stage 2 neurites that supported the translocation of axon-preferring kinesins. The behavior of rab11b-labeled dendritic vesicles in neurites 1 and 2 is of particular interest because both neurites originated as branches from a common segment; CA-Kinesin-1 accumulated only at the tip of branch 1 . There was abundant transport of dendritic vesicles in the common segment proximal to the branch point and along branch 2, but there were only a few short movements of dendritic vesicles along branch 1 suggesting that the modifications that inhibit dendritic transport and enhance CA-Kinesin-1 transport originate at the branch point that leads to neurite 1 .

In all, we analyzed the transport of rab11b-labeled vesicles in 10 Stage 2 cells (Fig. $7 D$ ). The number of anterograde transport events in neurites with little or no accumulation of CA-Kinesin-1 ( $\leq 20 \%$ of total CA-Kinesin-1 fluorescence in distal half of neurite; 33 of 45 neurites) averaged $1.2 \pm 0.7$ events $/ \mu \mathrm{m} / \mathrm{min}$. In contrast, there were $50 \%$ fewer anterograde movements of dendritic vesicles in neurites that accumulated CA-Kinesin- $1(\geq 20 \%$ CA-Kinesin- $1,0.6 \pm 0.3$ events $/ \mu \mathrm{m} / \mathrm{min} ; t$ test, $p<0.001$ ).

One of the most striking features of CA-Kinesin- 1 accumulation in Stage 2 cells is that it is dynamic, first occurring in one neurite, then leaving that neurite and accumulating in others; its locus of accumulation can change within tens of minutes (Jacobson et al., 2006). This observation indicates that the molecular signals that direct the transport of Kinesin-1 must also be dynamic. The strong inverse relationship between dendritic vesicle transport and the accumulation of CA-Kinesin-1 described above implies that the preferential transport of dendritic vesicles into a subset of Stage 2 neurites is also likely to be dynamic. To investigate this question directly, we recorded the transport of

$\leftarrow$

marker proteins. I, A composite line-scan showing the average distribution of each of these proteins along the proximal $70 \mu \mathrm{m}$ of the axon. AnkyrinG staining is enriched in a segment lying between 5 and $25 \mu \mathrm{m}$ from the cell body. MAP2 staining drops precipitously within the first 10 $\mu \mathrm{m}$ of the axon. Staining for polyglutamylated and acetylated tubulin and for Tau- 1 are enriched $\sim 20 \mu \mathrm{m}$ from the cell body and their levels continue to increase well beyond the initia segment. Contrast in images was nonlinearly adjusted to improve visibility in print. Based on $8-17$ cells for each condition. All neurons were imaged at 10-12 DIV. Scale bar, $20 \mu \mathrm{m}$. 
A Control B Control

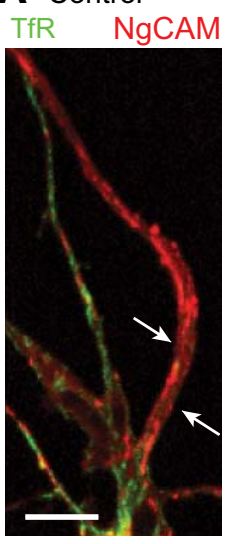

TfR-GFP

NgCAM-mCherry

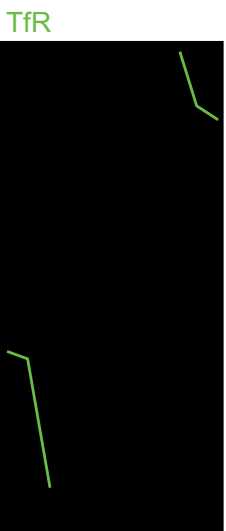

$\mathrm{NgCAM}$

TfR $\quad \mathrm{NgCAM}$
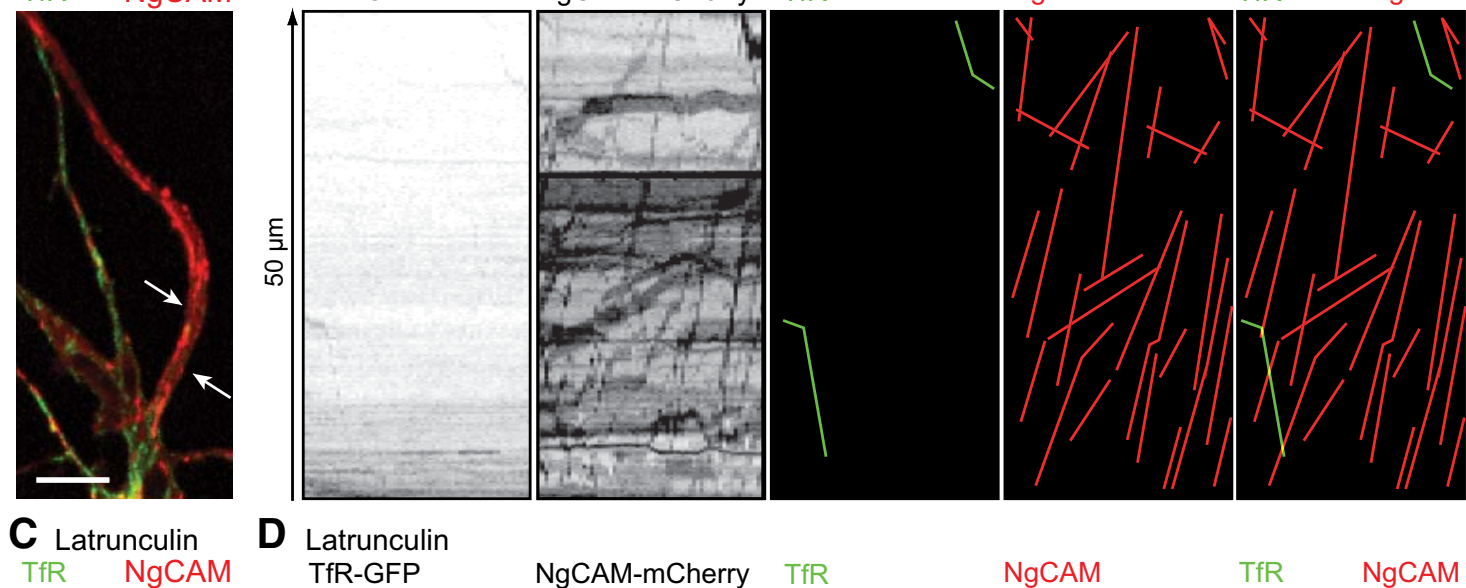

D Latrunculin
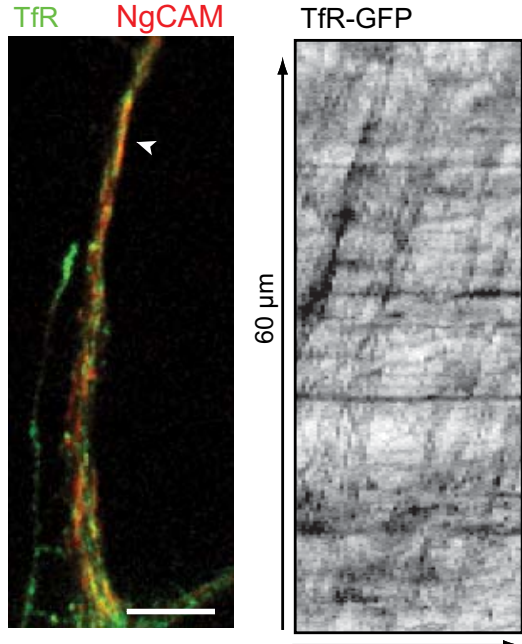

NgCAM-mCherry

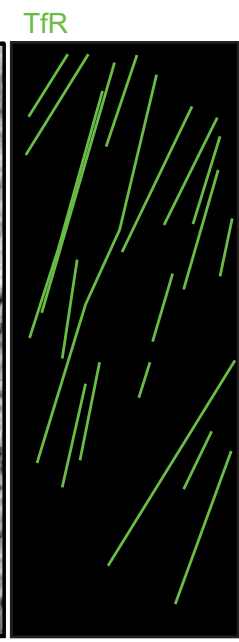

$\mathrm{NgCAM}$

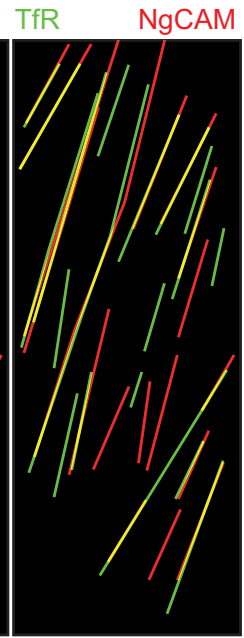

$66 \mathrm{sec}$

Figure 5. Latrunculin A causes the mis-sorting of TfR-GFP into axonal transport vesicles. $A$, A color overlay spinning disk image of the proximal axon (arrows) of a DMSO-control neuron $6-8 \mathrm{~h}$ after cotransfection of TfR-GFP and NgCAM-mCherry. The axon of this cell contains only NgCAM-mCherry. B, Kymographs from the axon of the cell shown in $\boldsymbol{A}$ contain no transport of TfR-GFP but abundant $\mathrm{NgCAM}$-mCherry transport. Lines highlighting TfR-GFP (green) or NgCAM-mCherry (red) vesicle movements are shown to the right. C, The proximal axon of a latrunculin A-treated neuron contains fluorescence for both NgCAM-mCherry and TfR-GFP. One large tubule containing both proteins in the axon is indicated by arrowhead. The recording of transport in these cells is shown in Movie 3. D, Kymographs of axonal transport in the axon of this cell show many anterograde movements of TfR-GFP and NgCAM-mCherry vesides. Lines highlighting TfR-GFP (green) or NgCAM-mCherry (red) veside movements are shown separately and overlaid to the right. A high degree of colocalization of proteins in the same transport vesicles is evident from the overlapping lines (yellow). Neurons at $8-10$ DIV were treated with latrunculin A ( $2.5 \mu \mathrm{m}$ in DMSO) or DMSO only (control) and imaged $2 \mathrm{~h}$ later. Contrast in images was nonlinearly adjusted to improve visibility of dim moving vesicles. Scale bar, $5 \mu \mathrm{m}$.

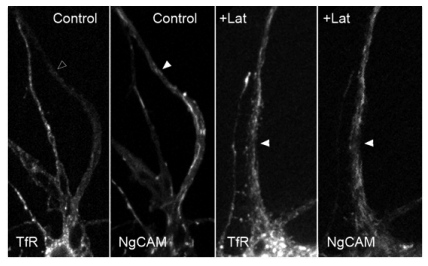

Movie 3. Actin depolymerization disrupts sorting of axonal and dendritic proteins into different transport organelles. The proximal axons of control and latrunculin A-treated neurons (10 DIV) coexpressing TfR-GFP and NgCAM-mCherry are shown. On the left, the open arrowhead indicates lack of transport of TfR-GFP in the axon of the control cell, whereas NgCAM readily transports into the control cell axon (solid arrowhead). To the right, the axon of a latrunculin A-treated cell (solid arrowheads) contains abundant transport of both TfR and NgCAM. Sequential stream time-lapse images of control or latrunculin A-treated neurons were acquired at $\sim 2$ frames per second for 120 frames. Movie is played at 30 frames per second.

rab11b-GFP vesicles in the same neuron at different times, to determine whether the amount of transport in different neurites changed over time and whether these changes were related to changes in the accumulation of CA-Kinesin-1.
Table 1. Treatment with latrunculin a alters the sorting of transferrin receptor into axonal transport vesicles

\begin{tabular}{lllc}
\hline & \multicolumn{3}{l}{ №. Transport Vesicles in the Axon ${ }^{a}$} \\
\cline { 2 - 4 } & $\begin{array}{l}\text { Labeled with } \\
\text { TfR-GFP }\end{array}$ & $\begin{array}{l}\text { Labeled with } \\
\text { NgCAM-mCh }\end{array}$ & $\begin{array}{l}\text { Labeled with } \\
\text { both (\%) }\end{array}$ \\
\hline Control (7 cells) & 7 & 71 & $2(2.5)$ \\
Latrunculin A (8 cells) & 30 & 43 & $59(44.7)$ \\
\hline
\end{tabular}

${ }^{a}$ Number of vesicles undergoing anterograde axonal transport, based on kymograph analysis.

An example is shown in Figure 8. At the beginning of this recording, CA-Kinesin-1 was concentrated at the tips of neurites 1 and 2 (Fig. 8A). After $189 \mathrm{~min}$, CA-Kinesin-1 had become concentrated in neurite 4 and was no longer detectable in neurites 1 and 2 (Fig. 8B). Kymographs show the anterograde traffic of GFP-rabl1vesicles in the neurites of the cell shown in Figure $8 A, B$ at the corresponding time points (Fig. $8 C, D$ ). The number of anterograde transport events increased markedly in the neurite that lost CA-Kinesin-1 (neurites1 and 2) and decreased substantially in the neurite that gained CA-Kinesin-1 accumulation 
A
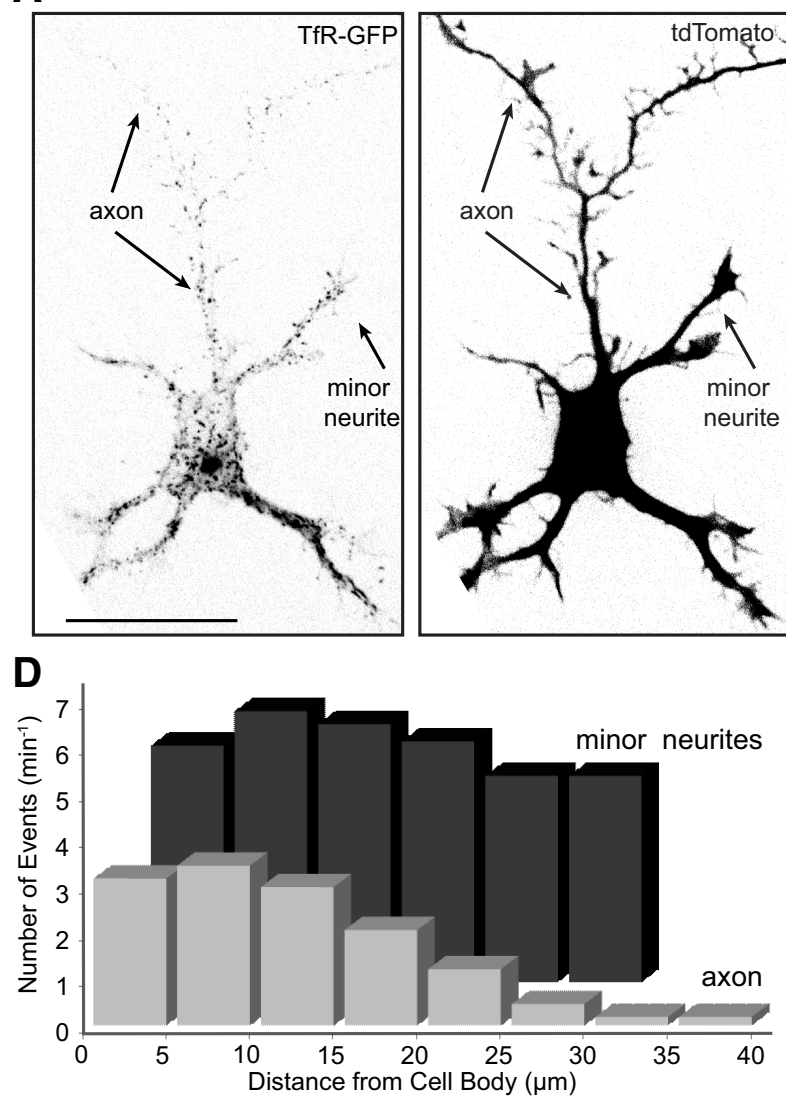

B
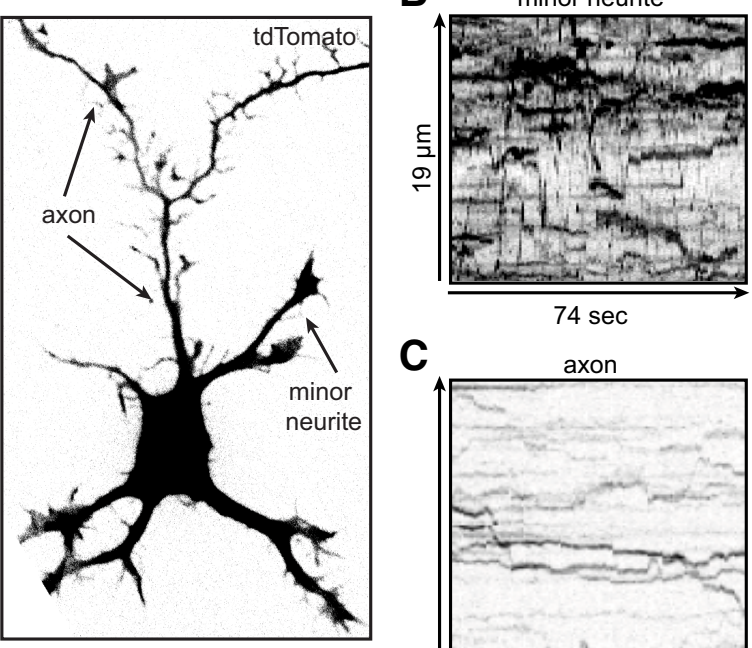

C

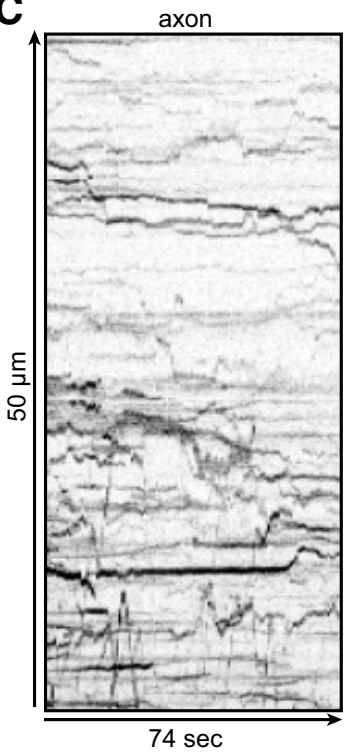

minor neurite

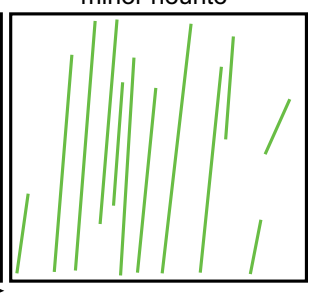

axon

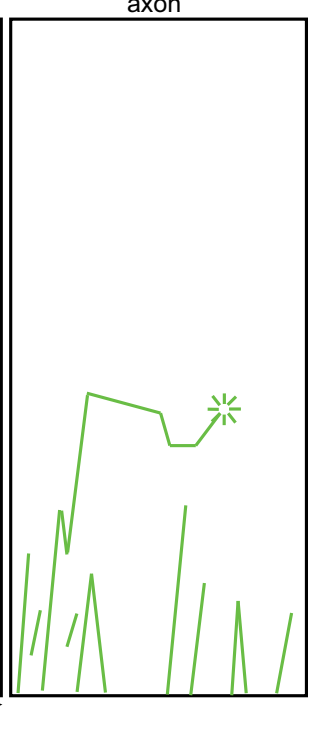

Figure 6. Selective transport of dendritic vesicles is present at early stages of development. A, A Stage 3 neuron (1 DIV) coelectroporated with TfR-GFP (left) and soluble tdTomato (right) to show cell morphology was live- imaged using a spinning disk confocal microscope to record movement of TfR-GFP labeled vesicles (Movie 4). B, C, Kymographs illustrating the transport of TfR-GFP in a minor neurite and in the axon. Anterograde transport events were traced as green lines to the right. There was extensive IfR transport in the minor neurites, but TfR-labeled vesicles did not advance beyond $25 \mu \mathrm{m}$ into the newly formed axon; the vesicles that entered the proximal axon either reversed direction or fused with the plasma membrane (asterisk). $\boldsymbol{D}, \mathrm{A}$ comparison of the number of anterograde transport events of TfR-GFP vesicles at different distances along the axon (light bars) and minor neurites (dark bars). In the axon, the amount of TfR transport drops off dramatically within $30 \mu \mathrm{m}$ from the cell body. In contrast, TfR-GFP is transported through the full-length of minor neurites (dark gray bars). Contrast in images was inverted and nonlinearly adjusted to improve visibility of dim moving vesicles. Neurons were imaged at $1 \mathrm{DIV} ; n=8$ cells. Scale bar, $20 \mu \mathrm{m}$.

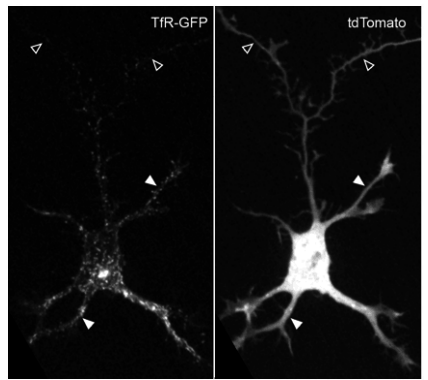

Movie 4. Dendrite-selective transport is present in newly formed axon. A neuron (1 DIV) coelectroporated with TfR-GFP (left) and soluble tdTomato (right) shows extensive TfR transport in the minor neurites (solid arrowheads), but TfR-labeled vesicles do not advance into the axon (open arrowheads). Stream time-lapse images were acquired at 2 frames per second for 120 frames. Movie is played at 10 frames per second.

(neurite 4). In recordings from three different Stage 2 cells (spanning intervals from 66 to $189 \mathrm{~min}$ ) we identified three neurites in which CA-Kinesin-1 became accumulated and two neurites which lost CA-Kinesin-1. In the three neurites that gained CAKinesin-1, transport decreased by $27 \%, 47 \%$, and $70 \%$, relative to the initial time point (based on the number of anterograde events $/ \mu \mathrm{m} / \mathrm{min})$. Conversely, in the two neurites that lost CAKinesin-1, transport increased to 121 and $288 \%$ of transport at the initial time point. These results show that transport of vesicles containing dendritic proteins is dynamically regulated during Stage 2 of development and that changes in the amount of dendritic transport are inversely related with the accumulation of CA-Kinesin-1, an axon-selective motor.

\section{Discussion}

Using live cell imaging to visualize the transport of vesicles containing different cargoes, we show that selective transport of vesicles containing dendritic proteins arises at Stage 3 of development, in concert with axon formation but well before the initial segment is established. As neurons mature and the initial segment specialization forms, the point at which the transport of dendritic vesicles is arrested becomes precisely aligned with the proximal edge of the initial segment. At all stages of development, vesicles containing axonal proteins move from the cell body out into the distal axon without any change in velocity. These observations have important implications for the mechanisms that underlie selective transport in both mature and developing neurons, as discussed below.

Features of dendrite-selective transport in mature neurons Our observations show that in mature neurons dendritic vesicles that enter the base of the axon stop when they reach the proximal 
A

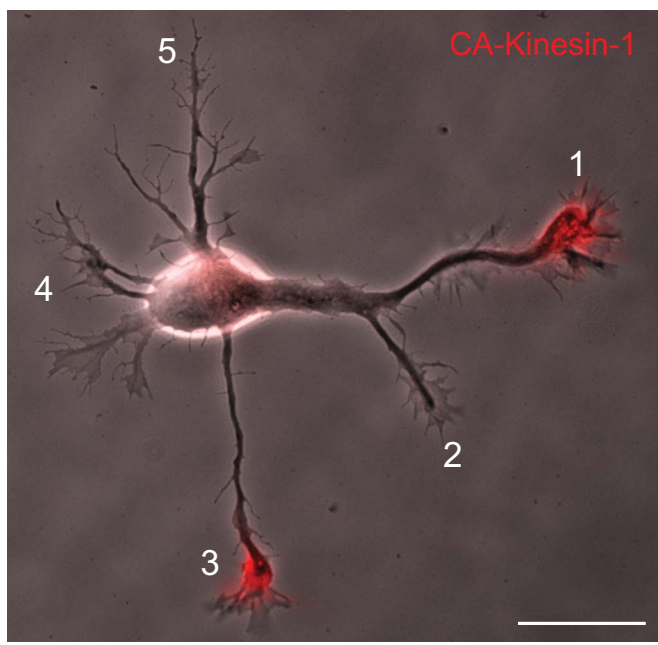

C

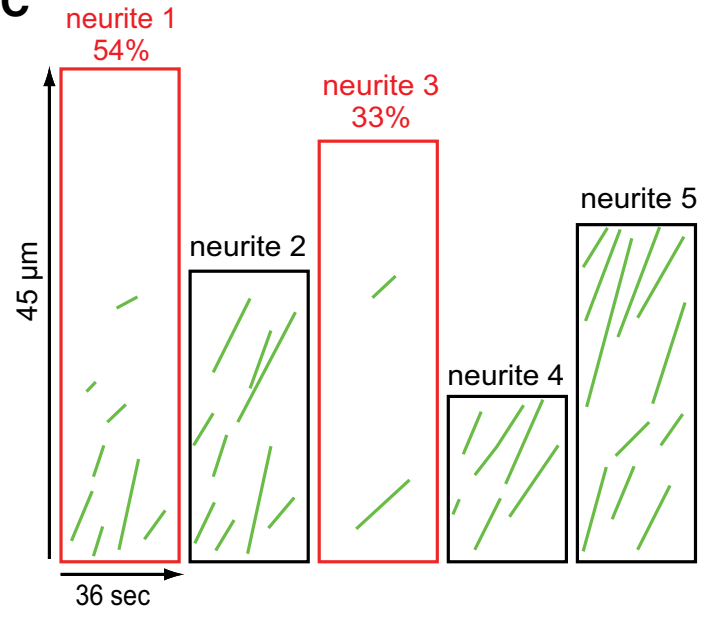

B

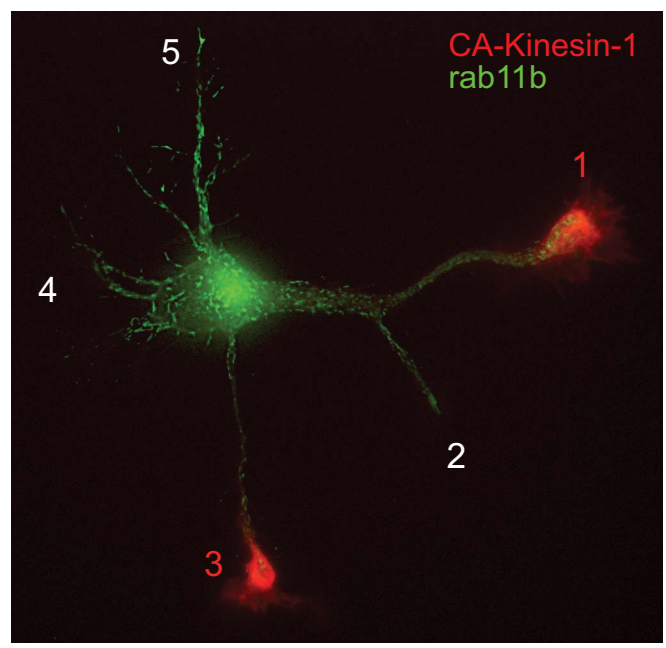

D

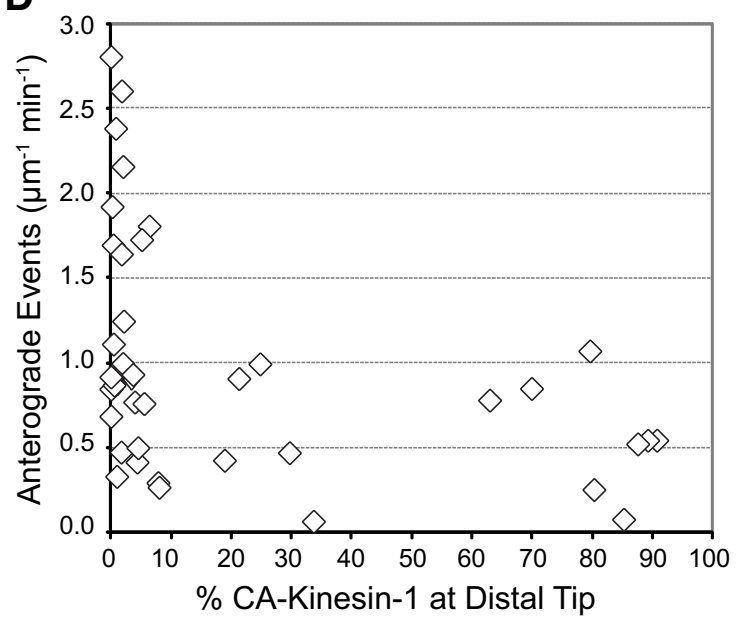

Figure 7. Vesicles containing dendritic proteins undergo selective transport before axon specification. $\boldsymbol{A}, \boldsymbol{B}$, Phase contrast and fluorescence images of a Stage 2 cell expressing $C A$-Kinesin-1tdTomato (red) and GFP-rab11b (green). CA-Kinesin-1 accumulated strongly at the tips of neurites 1 and 3. The corresponding video is shown in Movie 5. C, Anterograde events traced from kymographs show the anterograde transport of GFP-rab11b in each neurite. The kymographs outlined in red are taken from neurites 1 and 3 , which contain high amounts of CA-Kinesin-1. The percentage of total CA-Kinesin-1 fluorescence accumulated in each neurite is indicated above the kymographs. $\boldsymbol{D}$, The relationship between the fraction of (A-Kinesin accumulated in each neurite $(x$-axis) and the amount of rab11 transport in the same neurite ( $y$-axis). Neurites that contained significant amounts of CA-Kinesin-1 fluorescence ( $>20 \%)$ had significantly lower amounts of GFP-rab11b transport. Each symbol corresponds to a single neurite. Contrast in images was nonlinearly adjusted to improve visibility of dim moving vesicles. Neurons were imaged at $1 \mathrm{DIV} ; n=10$ neurons. Scale bar, $20 \mu \mathrm{m}$.

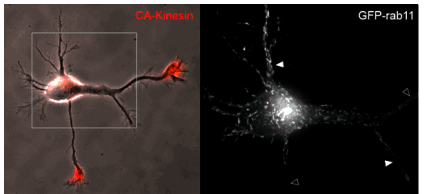

Movie 5. Dendrite-selective transport detected before axon specification. After $24 \mathrm{~h}$ in culture, a Stage 2 neuron coexpressing GFP-rab11b and CA-Kinesin1-tdTomato (red) is shown on the left in phase contrast with CA-Kinesin-1 overlaid. Transport of GFP-rab11 in the boxed area is shown to the right. Rab11 transports throughout neurites that do not contain accumulated CA-Kinesin-1 (solid arrowheads) but does not transport into neurites with CA-Kinesin-1 accumulation (open arrowheads). Stream time-lapse images were acquired at 1.67 frames per second for 60 frames. Movie is played at 15 frames per second.

edge of the initial segment, where they either pause and return to the cell body or fuse with the somatodendritic plasma membrane. Arnold and colleagues (Al-Bassam et al., 2012; Watanabe et al., 2012) and others have made similar observations. In contrast, axonal vesicles traverse this region of the cell without noticeable pause or deceleration. These observations are difficult to recon- cile with the cytoplasmic filter model (Song et al., 2009). First, neither dendritic nor axonal vesicles decelerate as they pass through the initial segment, as the filter model predicts. Instead, dendritic vesicles stop abruptly at the base of the axon whereas axonal vesicles do not decelerate at all. Second, the turnaround point for dendritic vesicles is at the proximal end of the initial segment, not within the initial segment itself where the enrichment in actin filaments has been described (Nakada et al., 2003; Song et al., 2009). The position of the turnaround point for dendritic vesicles more closely matches the point where MAP2positive dendritic microtubules end and where actin patches are found (Watanabe et al., 2012).

One key observation in support of models that depend on the enrichment of actin filaments in the initial segment is that depolymerization of actin allows dendritically polarized proteins to enter the axon (Lewis et al., 2009; Song et al., 2009). This finding has been taken as evidence that actin in the initial segment is required to exclude dendritic vesicles from the axon, but our findings point to an alternative explanation for these results. Normally, dendritic proteins are sorted into a distinct vesicle popu- 
A $\mathrm{t}=0 \mathrm{~min}$

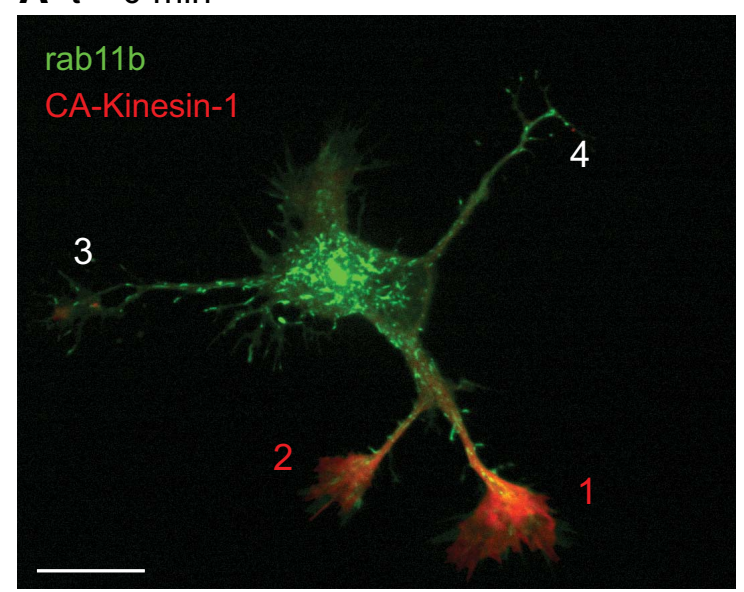

C$$
\text { C }
$$

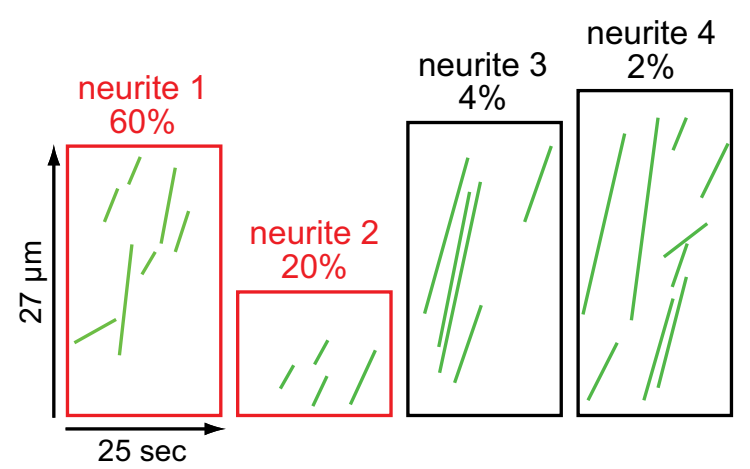

\section{B $\mathrm{t}=189 \mathrm{~min}$}

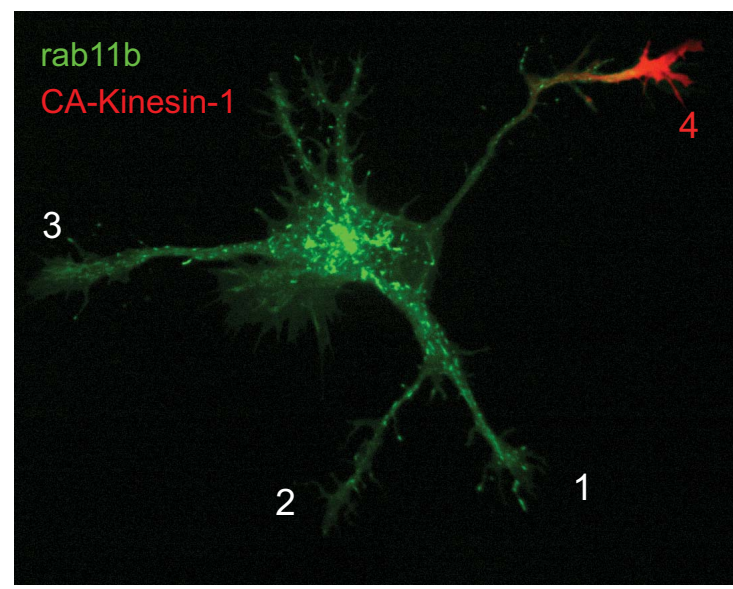

D

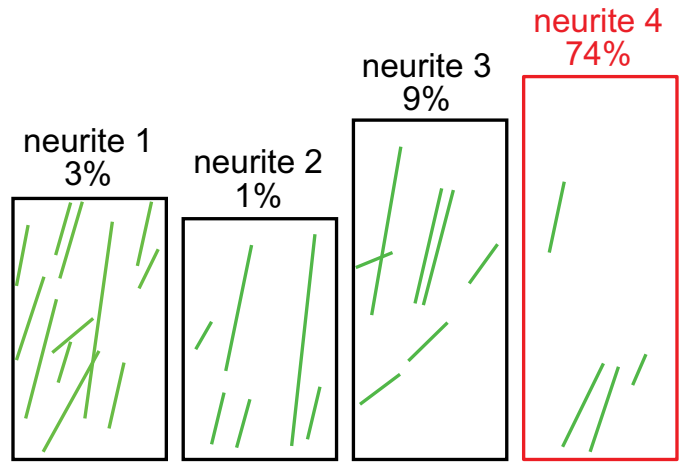

Figure 8. Selective dendritic transport is dynamic before axon specification. $\boldsymbol{A}$, Fluorescence overlay of a Stage 2 neuron coexpressing CA-kinesin-1-tdTomato (red) and GFP-rab11b (green). CA-Kinesin-1 accumulated selectively in neurites 1 and 2. B. The same cell imaged 189 min later. During this interval, CA-Kinesin-1 left neurites 1 and 2 and accumulated at the tip of neurite 4. Kymographs showing transport of rab11b-GFP at 0 min $(\boldsymbol{C})$ and 189 min later $(\boldsymbol{D})$ show that the loss of CA-Kinesin- 1 from neurites 1 and 2 was accompanied by an increase in rab11 transport, whereas the accumulation of CA-Kinesin-1 in neurite 4 was accompanied by a decrease in rab11 transport. This neuron was imaged at 1 DIV. Contrast in images was nonlinearly adjusted to improve visibility of dim moving vesicles. Scale bar, $20 \mu \mathrm{m}$.

lation by a clathrin- and AP-1-dependent process (Farías et al., 2012). Disrupting this process, either by mutating the sorting signals in dendritic proteins (Jareb and Banker, 1998; Silverman et al., 2001; Lasiecka et al., 2009) or by preventing the AP-1 complex from recognizing these signals (Farías et al., 2012), allows dendritic proteins to "leak" into the population of vesicles that deliver proteins to the axon, thus leading to a loss in protein polarization. Our two-color imaging results show that treating neurons with latrunculin also disrupts dendritic protein sorting. After latrunculin treatment, TfR is found in the same vesicles that are labeled by the axonal protein NgCAM, a finding that never occurs in intact neurons. Previous results indicate that actin plays a role in the process of vesicle budding from the Golgi complex (Carreno et al., 2004; Lázaro-Diéguez et al., 2007), where the sorting machinery is thought to act. Thus, the loss of polarity following actin depolymerization may not be due exclusively to disruption of the initial segment actin network; alterations in protein sorting that occur upstream of vesicle transport are also important.

\section{Changes in dendrite-selective transport during neuronal development}

Our findings demonstrate that selective dendritic transport arises early in neuronal development. At Developmental Stage 3, just after the period of extended outgrowth that marks the initial specification of the axon, vesicles containing dendritic proteins are already efficiently excluded from the axon. Approximately 10 times as many vesicles undergo anterograde transport into the minor neurites compared with the axon. The reversal point for dendritic vesicles is not as clearly defined as it is in mature neurons; some vesicles are transported as far as $20-30 \mu \mathrm{m}$ out into the axon, but beyond this point there is almost no anterograde movement of dendritic vesicles. As in mature neurons, the transport of axonal vesicles through the proximal axon is unimpeded. These observations have important implications for models of selective transport. At this stage of development many of the biochemical features that characterize axonal and dendritic microtubules are already in place and kinesin motor domains can distinguish between axonal and dendritic microtubules (Jacobson et al., 2006; Hammond et al., 2010; Huang and Banker, 2012). In contrast, there is no enrichment of initial segment markers, the cytoplasmic diffusion barrier between the cell body and the axon has not yet formed, and the dense actin meshwork at the base of the axon is not yet in place (Nakada et al., 2003; Song et al., 2009). The organization of actin at the base of newly formed axons has not yet been examined so it is unclear if there are enough appropriately organized actin patches to support myosin-based transport, as in the model of Arnold and colleagues (Al-Bassam et al., 2012; Watanabe et al., 2012).

These results are also inconsistent with the hypothesis that the selectivity of dendritic transport arises because dendritic trans- 
port is largely or entirely mediated by dynein (Kapitein et al., 2010). At Stage 3, the polarity orientation of microtubules in axons and dendrites is identical: $\sim 90 \%$ of axonal and dendritic microtubules are oriented plus-end out (Baas et al., 1989; Stepanova et al., 2003). If dendritic vesicles were transported by dynein, one would expect little or no transport of these vesicles into either the axon or the dendrites. Yet our observations show extensive transport into the dendrites, but little transport into the axon. The bidirectional transport observed in Stage 3 dendrites can only be explained if dendritic vesicles are transported by both kinesins and dyneins.

At Stage 2 of development, neurites have not yet been specified as axons or dendrites but some aspects of selective transport can already be observed. For example, the Kinesin-1 motor domain, which translocates preferentially on axonal microtubules in mature neurons, accumulates at the tips of only one or two neurites in Stage 2 neurons and its accumulation is dynamic. Over a period of 10-30 min, the motor domain can leave one neurite and accumulate in others. It is thought that these dynamic changes in kinesin motor domain accumulation reflect coordinated biochemical modifications to the microtubules in different neurites (Jacobson et al., 2006; Hammond et al., 2010). The observations presented here show that the transport of vesicles containing dendritic proteins is also selective at this stage of development. Two or three times more vesicles enter some neurites than others and the amount of dendritic vesicle transport in any given neurite is inversely correlated with the accumulation of the CA-Kinesin-1. Neurites with microtubules that are preferred substrates for CA-Kinesin-1 have less transport of dendritic vesicles, and vice versa. Moreover, when individual cells are followed over time the patterns of dendritic vesicle transport and of Kinesin-1 accumulation change in a coordinated fashion: an increase in dendritic vesicle transport in a given neurite is accompanied by a loss of Kinesin-1 accumulation and a decrease in dendritic vesicle transport is accompanied by an increase in Kinesin-1 accumulation.

\section{Conclusion}

Our results show that selective dendritic transport arises quite early in neuronal development. Some evidence of selective transport can be seen as early as Stage 2, and by Stage 3 the efficiency with which dendritic vesicles are excluded from the axon is approximately the same as in mature cells. The transport selectivity seen at Stage 2 of development likely reflects the affinity of microtubule motors for different populations of microtubules. Kinesins can detect differences between microtubules in different neurites at this stage (Jacobson et al., 2006; Hammond et al., 2010; Huang and Banker, 2012), but none of the other cues proposed to direct selective transport in mature neurons are yet in place. Posttranslational modifications of tubulin are probably involved in steering motors at this stage (Hammond et al., 2010), but definitive identification of the relevant microtubule cues will require better tools to analyze and manipulate tubulin modifications (Garnham and Roll-Mecak, 2012). Motor-microtubule interactions likely also contribute to selective transport at Stage 3, but other mechanisms may also come into play. During Stage 4 of development, when the initial segment forms and dendrites acquire a population of minus-end out microtubules, the turnaround point for dendritic vesicles becomes closely aligned with the proximal edge of the initial segment. At this stage, additional mechanisms to ensure the selectivity of dendritic transport may come into play. In mature neurons, dendrite-selective transport likely depends on the coordinated activity of multiple motors, since inhibiting transport mediated by myosin Va or dynein, or enhancing transport mediated by certain kinesins causes dendritic vesicles to enter the axon (Lewis et al., 2009; Kapitein et al., 2010; Al-Bassam et al., 2012; Jenkins et al., 2012).

\section{References}

Al-Bassam S, Xu M, Wandless TJ, Arnold DB (2012) Differential trafficking of transport vesicles contributes to the localization of dendritic proteins. Cell Rep 2:89-100. CrossRef Medline

Arnold DB (2009) Actin and microtubule-based cytoskeletal cues direct polarized targeting of proteins in neurons. Sci Signal 2:pe49. CrossRef Medline

Baas PW, Black MM, Banker GA (1989) Changes in microtubule polarity orientation during the development of hippocampal neurons in culture. J Cell Biol 109:3085-3094. Medline

Boiko T, Vakulenko M, Ewers H, Yap CC, Norden C, Winckler B (2007) Ankyrin-dependent and -independent mechanisms orchestrate axonal compartmentalization of L1 family members neurofascin and L1/ neuron-glia cell adhesion molecule. J Neurosci 27:590-603. CrossRef Medline

Burack MA, Silverman MA, Banker G (2000) The role of selective transport in neuronal protein sorting. Neuron 26:465-472. CrossRef Medline

Carreno S, Engqvist-Goldstein AE, Zhang CX, McDonald KL, Drubin DG (2004) Actin dynamics coupled to clathrin-coated vesicle formation at the trans-Golgi network. J Cell Biol 165:781-788. CrossRef Medline

Dotti CG, Sullivan CA, Banker GA (1988) The establishment of polarity by hippocampal neurons in culture. J Neurosci 8:1454-1468. Medline

Esch T, Lemmon V, Banker G (2000) Differential effects of NgCAM and $\mathrm{N}$-cadherin on the development of axons and dendrites by cultured hippocampal neurons. J Neurocytol 29:215-223. CrossRef Medline

Farías GG, Cuitino L, Guo X, Ren X, Jarnik M, Mattera R, Bonifacino JS (2012) Signal-mediated, AP-1/clathrin-dependent sorting of transmembrane receptors to the somatodendritic domain of hippocampal neurons. Neuron 75:810-823. CrossRef Medline

Garnham CP, Roll-Mecak A (2012) The chemical complexity of cellular microtubules: tubulin post-translational modification enzymes and their roles in tuning microtuble functions. Cytoskeleton 69:442-463. CrossRef Medline

Hammond JW, Huang CF, Kaech S, Jacobson C, Banker G, Verhey KJ (2010) Posttranslational modifications of tubulin and the polarized transport of kinesin-1 in neurons. Mol Biol Cell 21:572-583. CrossRef Medline

Hedstrom KL, Xu X, Ogawa Y, Frischknecht R, Seidenbecher CI, Shrager P, Rasband MN (2007) Neurofascin assembles a specialized extracellular matrix at the axon initial segment. J Cell Biol 178:875-886. CrossRef Medline

Hedstrom KL, Ogawa Y, Rasband MN (2008) AnkyrinG is required for maintenance of the axon initial segment and neuronal polarity. J Cell Biol 183:635-640. CrossRef Medline

Huang CF, Banker G (2012) The translocation selectivity of the kinesins that mediate neuronal organelle transport. Traffic 13:549-564. CrossRef Medline

Jacobson C, Schnapp B, Banker GA (2006) A change in the selective translocation of the Kinesin-1 motor domain marks the initial specification of the axon. Neuron 49:797-804. CrossRef Medline

Jareb M, Banker G (1997) Inhibition of axonal growth by brefeldin A in hippocampal neurons in culture. J Neurosci 17:8955-8963. Medline

Jareb M, Banker G (1998) The polarized sorting of membrane proteins expressed in cultured hippocampal neurons using viral vectors. Neuron 20:855-867. CrossRef Medline

Jenkins B, Decker H, Bentley M, Luisi J, Banker G (2012) A novel split kinesin assay identifies motor proteins that interact with distinct vesicle populations. J Cell Biol 198:749-761. CrossRef Medline

Kaech S, Banker G (2006) Culturing hippocampal neurons. Nat Protoc 1:2406-2415. CrossRef Medline

Kaether C, Skehel P, Dotti CG (2000) Axonal membrane proteins are transported in distinct carriers: a two-color video microscopy study in cultured hippocampal neurons. Mol Biol Cell 11:1213-1224. CrossRef Medline

Kapitein LC, Schlager MA, Kuijpers M, Wulf PS, van Spronsen M, MacKintosh FC, Hoogenraad CC (2010) Mixed microtubules steer dyneindriven cargo transport into dendrites. Curr Biol 20:290-299. CrossRef Medline 
Lasiecka ZM, Yap CC, Vakulenko M, Winckler B (2009) Compartmentalizing the neuronal plasma membrane from axon initial segments to synapses. Int Rev Cell Mol Biol 272:303-389. CrossRef Medline

Lázaro-Diéguez F, Colonna C, Cortegano M, Calvo M, Martínez SE, Egea G (2007) Variable actin dynamics requirement for the exit of different cargo from the transGolgi network. FEBS Lett 581:3875-3881. CrossRef Medline

Lewis TL Jr, Mao T, Svoboda K, Arnold DB (2009) Myosin-dependent targeting of transmembrane proteins to neuronal dendrites. Nat Neurosci 12:568-576. CrossRef Medline

Nakada C, Ritchie K, Oba Y, Nakamura M, Hotta Y, Iino R, Kasai RS, Yamaguchi K, Fujiwara T, Kusumi A (2003) Accumulation of anchored proteins forms membrane diffusion barriers during neuronal polarization. Nat Cell Biol 5:626-632. CrossRef Medline

Nakata T, Hirokawa N (2003) Microtubules provide directional cues for polarized axonal transport through interaction with kinesin motor head. J Cell Biol 162:1045-1055. CrossRef Medline

Niwa H, Yamamura K, Miyazaki J (1991) Efficient selection for highexpression transfectants with a novel eukaryotic vector. Gene 108:193199. Medline

Palay SL, Sotelo C, Peters A, Orkand PM (1968) The axon hillock and the initial segment. J Cell Biol 38:193-201. CrossRef Medline

Schlierf B, Fey GH, Hauber J, Hocke GM, Rosorius O (2000) Rabl1b is essential for recycling of transferrin to the plasma membrane. Exp Cell Res 259:257-265. CrossRef Medline

Setou M, Seog DH, Tanaka Y, Kanai Y, Takei Y, Kawagishi M, Hirokawa N (2002) Glutamate-receptor-interacting protein GRIP1 directly steers kinesin to dendrites. Nature 417:83-87. CrossRef Medline

Shaner NC, Campbell RE, Steinbach PA, Geipmans BN, Palmer AE, Tsien RY (2004) Improved monomeric red, orange and yellow fluorescent proteins derived from Discosoma sp. red fluorescent protein. Nat Biotechnol 22: 1567-1572. CrossRef Medline

Silverman MA, Kaech S, Jareb M, Burack MA, Vogt L, Sonderegger P, Banker G (2001) Sorting and directed transport of membrane proteins during development of hippocampal neurons in culture. Proc Natl Acad Sci U S A 98:7051-7057. CrossRef Medline

Sobotzik JM, Sie JM, Politi C, Del Turco D, Bennett V, Deller T, Schultz C (2009) AnkyrinG is required to maintain axo-dendritic polarity in vivo. Proc Natl Acad Sci U S A 106:17564-17569. CrossRef Medline

Song AH, Wang D, Chen G, Li Y, Luo J, Duan S, Poo MM (2009) A selective filter for cytoplasmic transport at the axon initial segment. Cell 136:11481160. CrossRef Medline

Stepanova T, Slemmer J, Hoogenraad CC, Lansbergen G, Dortland B, De Zeeuw CI, Grosveld F, van Cappellen G, Akhmanova A, Galjart N (2003) Visualization of microtubule growth in cultured neurons via the use of EB3-GFP (end-binding protein 3-green fluorescent protein). J Neurosci 23:2655-2664. Medline

Szu-Yu Ho T, Rasband MN (2011) Maintenance of neuronal polarity. Dev Neurobiol 71:474-482. CrossRef Medline

Watanabe K, Al-Bassam S, Miyazaki Y, Wandless TJ, Webster P, Arnold DB (2012) Networks of polarized actin filaments in the axon initial segment provide a mechanism for sorting axonal and dendritic proteins. Cell Rep 2:1546-1553. CrossRef Medline

Winckler B, Mellman I (1999) Neuronal polarity: controlling the sorting and diffusion of membrane components. Neuron 23:637-640. CrossRef Medline

Winckler B, Forscher P, Mellman I (1999) A diffusion barrier maintains distribution of membrane proteins in polarized neurons. Nature 397: 698-701. CrossRef Medline

Wisco D, Anderson ED, Chang MC, Norden C, Boiko T, Fölsch H, Winckler B (2003) Uncovering multiple axonal targeting pathways in hippocampal neurons. J Cell Biol 162:1317-1328. CrossRef Medline

Xu K, Zhong G, Zhuang X (2013) Actin, spectrin, and associated proteins form a periodic cytoskeletal structure in axons. Science 339:452-456. CrossRef Medline

Yang Y, Ogawa Y, Hedstrom KL, Rasband MN (2007) BetaIV spectrin is recruited to axon initial segments and nodes of Ranvier by ankyrinG. J Cell Biol 176:509-519. CrossRef Medline 